\title{
DEFINITIONS OF COMPONENTS OF THE WATER DATA SOURCES DIRECTORY MAINTAINED BY THE NATIONAL WATER DATA EXCHANGE
}

By Melvin D. Edwards

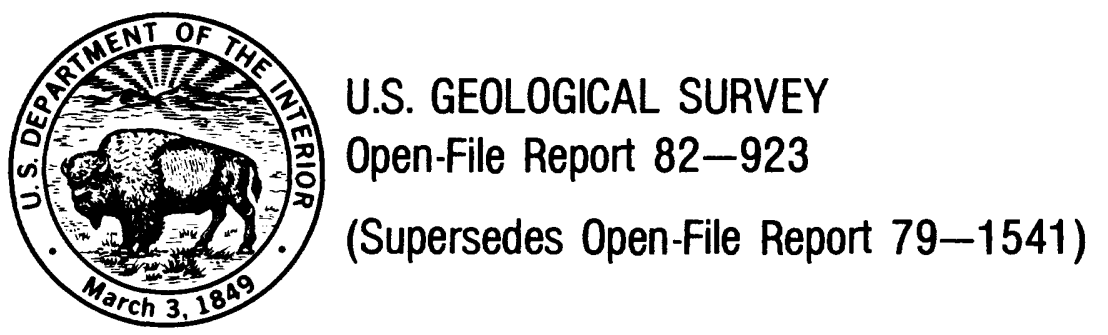




\section{UNITED STATES DEPARTMENT OF THE INTERIOR JAMES G. WATT, Secretary}

\section{GEOLOGICAL SURVEY}

Dallas L. Peck, Director

For additional information write to:

Chief Hydrologist

U.S. Geological Survey, WRD

421 National Center

Reston, Virginia 22092 
The National Water Data Exchange (NAWDEX) is an interagency program to facilitate the exchange of water data and to promote the standardization of water-data-handling procedures. Participants in the NAWDEX program consist of Federal, State, and local governmental organizations, and private organizations that collect and use water data.

MAWDEX maintains a "Water Data Sources Directory" which is a computerized index of water resources organizations. The Directory provides answers to: What kinds of water data are available? Who has the data? Where can the data be obtained?

This document defines the data components contained in the Water Data Sources Directory (WDSD); it is referred to as the "dictionary." Its purpose is to describe, in detail, the Information in the WDSD.

Inquiries related to the dictionary may be directed to:

Program Manager

National Water Data Exchange

U.S. Geological Survey

421 National Center

Reston, Virginia 22092

Telephone: 703-860-6031

FTS 928-6031 



\section{CONTENTS}

Page

III

Preface

Introduction-

Overview of the Water Data Sources Directory

Data base description-

Data base structure

How to use this document

Acknowledgment

Water Data Sources Directory component definitions-

Organization data (components 1-10)

Office data (components 100-124)

Assistance Center data (components 125-127)

Office comments (components 150-152)

Office stored data (components 200-218)

Office counties (components 275-276)

Organization stored data (components 400-418)

Organization counties (components 475-476)

Other source data (components 500-523)

Other source comments (components 550-552)

Liaison office data (components 1000-1018)

Liaison states of jurisdiction (components 1020-1022)

Liaison office comments (components 1050-1052)

Master Water Data Index data (components 1500-1518)

Master Water Data Index countles (components 1575-1576)

Water-Related Data (components 1600-1618)

Selected references 


\section{ILLUSTRATIONS}

Page

Figure 1. Hierarchical structure and contents of the Master Water Data Index data base-

2. Hierarchical structure of the Water Data Sources Directory data base-____-

3. Format of a component description 


\section{DEFINITIONS OF COMPONENTS OF THE WATER DATA SOURCES DIRECTORY MAINTAINED BY THE NATIONAL WATER DATA EXCHANGE}

By

Melvin D. Edwards

\section{INTRODUCTION}

The Water Data Sources Directory (WDSD) is a computerized data base developed and maintained by the National Water Data Exchange (NAWDEX) Program office which contains information about organizations that collect, store, and disseminate water data and water-related data. This includes: The type of each organization; the major orientation of water-data activities conducted by each organization; the names, addresses, and telephone numbers of offices within each organization from which water data may be obtained; the types of data held by each organization and the geographic locations within which these data have been collected; alternate sources of an organization's data; the designation of liaison personnel in matters related to water-data acquisition and indexing; the volume of water data indexed for the organization; and information about other types of data and services avallable from the organization that are pertinent to water-resource activities. This document contains a definition and description of each component of the WDSD data base. For simplicity, it is referred to as a data "dictionary." It is intended, primarily, to assist those persons using the WDSD in understanding and clarifying information obtained from the data base.

The WDSD is designed to be used independently, or in conjuction with, the Master Water Data Index (MWDI). The MWDI is also a computerized data base developed and maintained by the NAWDEX Program office. It contains detailed information about sites at which water data are collected: Identification and location of a site; the type of site; the organization operating the site; the current status of data collection at the site; the period of record available for the site; the major surface-water or ground-water parameters, water-quality parameters, and meteorological parameters measured at the site and the frequency of measurement of these parameters; and the media in which data are available for the site. A few components are common in both data bases, thereby allowing retrieved information to be cross-referenced between them. For example: A retrieval may be made from the MWDI to identify all sites within a geographic area of interest for which water quality data are available. A retrieval can, then, be made from the WDSD to determine the addresses from which the data may be obtained from organizations operating the identified sites. The hierarchical structure and content of the MWDI are shown in figure 1, page 123. A complete description of the MWDI can be found in the publication entitled "Definitions of Components of the Master Water Data Index Maintained by the National Water Data Exchange." 
The Water Data Sources Directory (WDSD) contains the following general categories of information:

Organization Description

Unique identifier

Name of organization

NAWDEX membership

Type of organization

Orientation of the organization's activities

Office Description

Unique Identifier

Name of office

Address

Telephone number

Areal coverage of data

Media used for data storage

State(s) and counties having data

General comments

Local Assistance Center information

Data Holdings of the Organization

Country, State, and counties for which data are avallable

Types of data available

Alternate Sources of the Organization's Data

Name of the alternate source

Address

Types of data available

Media used for data storage

General comments

Information about Liaison Officials for Water-Data Acquisition and Indexing Activities

Data Indexed in the MWDI

Water-Related Data Holdings of the Organization

Types of data avallable

Period of record

Number of sites or observations

Geographic area covered

Frequency of measurement

Media used for data storage

Other organizations that are sources of the data

As the NAWDEX program progresses, additional categories of data, or additional data items, will be added to the WDSD. Future editions of this dictionary will reflect any additions or changes to the WDSD. 


\section{Data Base Structure}

The WDSD data base is managed and maintained by the SYSTEM 20001] generalized Data Base Management System. The data in a SYSTEM 2000 data base are organized into a hierarchical structure, as shown in figure 2, page 125. All of the data about a single organization comprises a logical entry in the data base. Each organization, therefore, is a single separate logical entry in the WDSD. Individual pieces of information, such as the name of an organization or the address of an office, are known as data components; logically related data elements are grouped into blocks called schema records. A logical entry, therefore, may be composed of one or more schema records, each of which consists of one or more data components.

A fundamental aspect of a schema record is that the data it describes can occur once, many times, or not at all. For example, office information is stored in the OFFICE schema record. Because an organization may have many offices, the OFFICE schema record may occur many times, once for each office of the organization. Conversely, if there are no alternate sources of an organization s data, there will be no occurence of the OTHER SOURCE schema record for the organization.

A11 components of a SYSTEM 2000 data base have a unique name and number (unique within the data base). Figure 2 illustrates the number and name of every component and schema record in the WDSD. An asterisk separates each number from its corresponding name. Data components are organized by their respective schema records, and each box in figure 2 represents a schema record, with its number and name at the top of the box.

HOW TO USE THIS DOCUMENT

This document contains a detailed explanation of each schema record and data component of the WDSD. It is organized in the same order as the WDSD data base, with descriptions of data components belonging to the same schema record being located together. Each page in this document describes one schema record or data component. A user searching for the description of a particular data component should use figure 2 to determine its schema record, then find the page number of that schema record in the table of contents. The description of the data component follows the description of the schema record.

At the top of each page, certain attributes of the data component defined are listed to provide information generally needed only by data processing personnel for software development. These include IN SR, DATA TYPE, PICTURE, and LARGEST VALUE. A full definition of each of these attributes is found below. For the majority of users it will only be necessary to consider these attributes when producing a report or formulating a complex retrieval using

1 SYSTEM 2000 is a registered trademark of Intel Corp., and its mention does not constitute endorsement by the U.S. Geological Survey. 
the SYSTEM 2000 Immediate Access retrieval 1anguage. In other words, the majority of users need not be concerned with these attributes.

The attributes with which all users should be concerned are COMPONENT NAME, COMPONENT NUNBER, and KEY. COMPONENT NAME and COMPONENT NUMBER are simply labels for the component and may be used interchangeably by the user whenever referring to a component. The KEY attribute is an indicator of the relative expense and response time the user can expect when formulating a retrieval using the component in a conditional selection clause. For most cases, using key components ( $K E Y=$ Yes) instead of non-key components (KEY=No), in specifying the selection criteria for a data base retrieval will result in faster response and lower expense. Additional information on the use of attributes may be obtained from the SYSTEM 2000 Reference Manual.

Figure 3 illustrates the format used to describe WDSD components. Following is an explanation of each part of the description.

IN SR - A number appears here, which is the number of the schema record (SR) to which the schema record or data component belongs. For example, the top level schema record, as shown in figure 2, 18 schema record 0 . Data components 1 through 9 belong to schema record 0 , as do schema records $100,400,500,1000,1500$, and 1600 . All data components that belong to the same schema record appear together in this document.

COMPONENT NAME - The unfque name of the schema record or data component as used in the data base.

COMPONENT NUMBER - The unique number of the schema record or data component as used in the data base.

MANDATORY - Marked either "Yes" or "No." If "Yes", a value for the data component must be present in every occurrence of the schema record. For example, data component 1, NAWDEX AGCY, is mandatory because it is the unique identification code of the organization and, therefore, must always be present. On the other hand, data component 403, SW QLTY, 18 not mandatory because not every organization operates surface water quality sites and, therefore, the data component may be null (nonvalued).

KEY - Marked efther "Yes" or "No." In SYSTEM 2000, certain data components are designated by the designer of the data base as KEY to provide efficlencles in data retrieval. However, any data component, whether KEY or not, can be retrieved from the WDSD. This designation is not used for schema records.

DATA TYPE - Contains either CHAR, TEXT, INTEGER, DECIMAL, or DATE, depending on what type of data are stored for the component. CHAR and TEXT are used to store alphanumeric data (any character recognized by the computer), the difference being that TEXT retains leading and trailing blanks and multiple blanks between words, and CHAR does not. INTEGER and DECIMAL store whole numbers and decimal numbers, respectively, and DATE stores dates in the MM/DD/YYYY format. This notation is not applicable to schema records. 
NAWDEX

WATER DATA SOURCES DIRECTORY

DATA DICTIONARY

\section{$\overline{\text { IN SR }}$}

MANDATORY

PICTURE

Data Values
COMPONENT NAME

KEY

LARGEST OR LONGEST VALUE $\overline{\text { COMPONENT NUMBER }}$

DATA TYPE

$\longrightarrow$

Genera1 Description

Figure 3.--Format of a component description. 
PICTURE - Describes the "storage capacity" of the data component, using X(n) or $9(n)$ notation. Data components that are CHAR and TEXT have PICTURE lengths of $X(n)$, where " $n$ " is the total number of characters. For example, $X(23)$ indicates that typically up to 23 characters are stored for the data component. $X$ indicates that only one character may be stored for the data component. INTEGER uses $9(n)$ to indicate the total number of digits that can be stored. For DECIMAL data components, $9(n) \cdot 9(n)$ Indicates places to the left and right of the decimal point. DATE is always MM/DD/YYYY, where MM equals month, DD equals day, and YYYY equals year, and, therefore, PICTURE designation is unnecessary. Schema records do not have a PICTURE designation.

LARGEST OR LONGEST VALUE - This is the largest value that is allowed for the data component. For example, the largest value of a component designated as PICTURE 9(4) may be 5075 because of editing standards placed on data input to the data base. For data components defined as CHAR or TEXT, the largest value is allowed to exceed the PICTURE size because of the SYSTEM 2000 "overflow" capability. An example of this is data component 2, ORG NAME, which is PICTURE $X(23)$ but which may contain names up to 40 characters 1ong.

DATA VALUES - This is a narrative definition of the values that can be stored for a data component.

GENERAL DESCRIPTION - This is a narrative description of the type of data stored for a data component, its purpose, and the source or usefulness of the data. If a coding scheme is used, the meaning of each code is explained.

\section{ACKNOWLEDGMENT}

This document is a revision of a prior document with the same title. Acknowledgment is given to Mr. William A. Knecht of CACI, Inc., who coauthored the original document. 
WATER DATA SOURCES DIRECTORY COMPONENT DEF INITIONS 
$\frac{\mathrm{N} / \mathrm{A}}{\mathrm{IN} \mathrm{SR}}$

MANDATORY N/A

PICTURE N/A $\frac{\text { ORGANIZATION }}{\text { COMPONENT NAME }}$

KEY N/A
DATA TYPE

COMPONENT NUMBER SR

N /A

Data Values - Information that Identifies and describes the water-related activities of the organization.

This schena record is the highest level of the hierarchical structure and, therefore, represents the logical entry of a single organization into the data base. 
$\frac{0}{\text { IN SR }}$

MANDATORY Yes

PICTURE $\quad X(5)$
NAWDEX_AGCY

COMPONENT NAME

KEY

Yes
1

COMPONENT NUMBER

DATA TYPE Char

Data Values - The NAWDEX agency code varies in length from three to five characters. For Federal organizations, it is US followed by a two- or three-character abbreviation of the organization's name. Values for non-Federal organizations whose activities are within a given State boundary have a two-character alphabetic state code followed by a NAWDEX-assigned sequence number. Values for non-Federal organizations having activities at the multistate or national level have a three- to five-character abbreviation of the organization name (the characters US will not appear in the first two character positions). Alphabetic State codes are contained in the Federal Information Processing Standards (FIPS) Publication 5-1, dated June 15, 1970, and entitled "States and Outlying Areas of the United States." NAWDEX agency codes are presented in the publication entitled "Identification Codes for Organizations Listed in Computerized Data Systems of the U.S. Geological Survey" which may be obtained from the National Water Data Exchange, U.S. Geological Survey, 421 National Center, Reston, Virginia 22092. Telephone: (703) 860-6031; FTS 928-6031.

General Description - The NAWDEX agency code is assigned by the NAWDEX Program Office and is the unique identifier for participating Federal and non-Federal organizations that actively collect and store water data. Non-Federal organizations include State, county, and municlpal agencies, as well as intergovernmental compacts, private organizations, universities, and any local organizations at other than county or municipal level. 
$\frac{0}{\text { IN SR }}$

MANDATORY No

PICTURE $\mathrm{X}(23)$
ORG_NAME

COMPONENT NAME

KEY No

LARGEST OR LONGEST VALUE

$\frac{2}{\text { COMPONENT NUMBER }}$

DATA TYPE Char

Data Values - The name of the organization may contain up to 40 characters.

General Description - The name is the official name of the organization as it should appear on correspondence addressed to the organization. 
$\frac{0}{\text { IN SR }}$

MANDATORY No

PICTURE $\quad \mathrm{X}$
NAWDEX_MBR

COMPONENT NAME

KEY No

LARGEST OR LONGEST VALUE $\frac{3}{\text { COMPONENT NUMBER }}$

DATA TYPE Char

Data Values - This component is valued with " $N$ " if the organization is not a member of NAWDEX, or with " $\mathrm{Y}$ " if it is a member.

General Description - Membership in NAWDEX is voluntary and open to any water-oriented organization that wishes to take an active role in its activities. To be a member, a signed Memorandum of Understanding is required between the NAWDEX Program Office and the member organization. For those organizations that have become members, this component is valued "Y." For all other organizations it is valued "N." 
$\frac{0}{\text { IN SR }}$

MANDATORY

Yes
TYPE

COMPONENT NAME

KEY

No $\frac{4}{\text { COMPONENT NUMBER }}$

DATA TYPE Char
One-1etter NAWDEX TYPE Code

PICTURE

$\mathrm{X}$

LARGEST OR LONGEST VALUE

Data Values - The TYPE component contains a one-character alphabetic code used to classify an organization into one of the categories explained below.

General Description:

\begin{tabular}{|c|c|c|}
\hline Code & & Meaning \\
\hline C & County - & $\begin{array}{l}\text { A single organization, typically governmental, whose } \\
\text { scope of activity is encompassed by the boundaries of one } \\
\text { or more counties but does not cover an entire State. }\end{array}$ \\
\hline $\mathbf{F}$ & Federal - & $\begin{array}{l}\text { An agency or agencies of the Federal government or a } \\
\text { multi-country organization operating at the Federal } \\
\text { level. }\end{array}$ \\
\hline G & Intergover & $\begin{array}{l}\text { mental - An organization made up of different govern- } \\
\text { ment agencies, such as Federal-State compacts, } \\
\text { State-State compacts, multicounty compacts, river } \\
\text { basin commissions, etc. The scope of all the agencies } \\
\text { involved is only within the United States. }\end{array}$ \\
\hline I & Internatio & $\begin{array}{l}\text { la1 - An organization made up of representatives from } \\
\text { different countries, such as UNESCO, WHO, etc. }\end{array}$ \\
\hline $\mathbf{L}$ & Local - & $\begin{array}{l}\text { A local governmental organization other than county } \\
\text { or municipal. }\end{array}$ \\
\hline M & Municipa1 & A single municipal governmental organization. \\
\hline $\mathbf{P}$ & Private - & $\begin{array}{l}\text { An organization that cannot be classified as a } \\
\text { governmental organization. }\end{array}$ \\
\hline $\mathbf{S}$ & State & $\begin{array}{l}\text { A single governmental organization whose scope of activity } \\
\text { is encompassed by the boundaries of a single State. }\end{array}$ \\
\hline
\end{tabular}


$\frac{0}{\mathrm{IN} \mathrm{SR}}$

MANDATORY Yes

PICTURE
TYPE (continued)

COMPONENT NAME

KEY No

DATA TYPE Char

One-letter NAWDEX

LARGEST OR LONGEST VALUE

\begin{tabular}{|c|c|c|}
\hline Code & & Meaning \\
\hline U & University & $\begin{array}{l}\text { or Research Institute - An educational institution (public } \\
\text { or private) at the university or college level, or a non- } \\
\text { profit organization engaged in research. }\end{array}$ \\
\hline 0 & Other - & $\begin{array}{l}\text { An organization that cannot be classified into one of the } \\
\text { other categories. If this component is valued as " } 0 \text { " } \\
\text { (the alphabetic character } 0 \text { and not zero) then component } \\
\text { number } 5 \text {, OTHR TYPE, contains a description of the type } \\
\text { of organization. }\end{array}$ \\
\hline
\end{tabular}


0

$\overline{\text { IN SR }}$

MANDATORY No

PICTURE X(4)
OTHR TYPE

COMPONENT NAME

KEY

No

LARGEST OR LONGEST VALUE $\frac{5}{\text { COMPONENT NUMBER }}$

DATA TYPE Char

Data Values - If the organization is a type that cannot be classified into one of the categories in component number 4, TYPE, then this component contains a description of the type of organization up to 12 characters in length. It is valued only if component number 4 is valued as " 0 " (Other).

Genera1 Description - Descriptions of "other" types of organizations are entered by the NAWDEX Program Office based on information supplied by the organizations. 
$\frac{0}{\text { IN SR }}$

MANDATORY Yes

PICTURE
ORIENTATION1

COMPONENT NAME

KEY Yes

LARGEST OR LONGEST VALUE
6

COMPONENT NUMBER

DATA TYPE Char

One-character NAWDEX orientation code

Data Values - This component contains a one-character alphabetic code that describes the primary orientation of the organization's water-related activities.

Genera1 Description:

Code

A

B

D

E

F

$\mathrm{H}$

I

M

N

$\mathbf{P}$

R

S

$\mathrm{T}$

W

0

\section{Meaning}

Agriculture and Irrigation

Basic Hydrologic Research

Domestic, Rural

Evaluation of Resources

Flood Control

Hydroelectric

Industry

Multiple Source Public Supply

Navigation

Pollution Studies

Recreation

Single Source Public Supply

Thermoelectric

Fish and Wildlife

Other

If this component is valued as " 0 " (the alphabetic character 0 and not zero) then component number 8, OTHR ORNTN, contains a description of the orientation of the organization's water-related activities. 
$\frac{0}{\text { IN SR }}$

MANDATORY No

PICTURE

X
ORIENTATION2

COMPONENT NAME

KEY Yes

LARGEST OR LONGEST VALUE $\frac{7}{\text { COMPONENT NUMBER }}$

DATA TYPE Char

One-character NAWDEX orientation code

Data Values - This component contains a one-character alphabetic code that describes the secondary orientation of the organization's water-related activities, in the event that a single designation (in component 6, ORIENTATION1) is inadequate to describe those activities.

General Description - The same alphabetic codes used for ORIENTATION1 (component number 6 ) are used for ORIENTATION2. 
$\frac{0}{\text { IN SR }}$

MANDATORY No

PICTURE
OTHR ORNTN

COMPONENT NAME

KEY No

LARGEST OR LONGEST VALUE

$\frac{8}{\text { COMPONENT NUMBER }}$

DATA TYPE Char

Data Values - This component contains up to a 12-character description of the orientation of the organization's water-related activities. It is valued only if either component number 6 or component number 7 is valued as " 0 " (Other).

General Description - Descriptions of "other" types of orientations are entered by the NAWDEX Program office based on Information supplied by the reporting organization. 
$\frac{0}{\text { IN SR }}$

MANDATORY Yes

PICTURE MMDDYYYY
LAST UPDATE

COMPONENT NAME

KEY

No

LARGEST OR LONGEST VALUE $\frac{9}{\text { COMPONENT NUMBER }}$

DATA TYPE Date

Data Values - Contains the month, day, and year of the last date (MM/DD/YYYY) that an update of any type was processed against the organization's entry in the data base.

General Description - An update is defined as any transaction that adds, deletes, or changes data values in the WDSD data base. If no updates have been made to the data about an organization, the LAST UPDATE is the date on which the data was first inserted into the data base. 
0

$\overline{\text { IN SR }}$

MANDATORY Yes

PICTURE X(10)
DIRECTORY_TYPE

COMPONENT NAME

KEY Yes

LARGEST OR LONGEST VALUE
10

COMPONENT NUMBER

DATA TYPE Char

\section{Data Values}

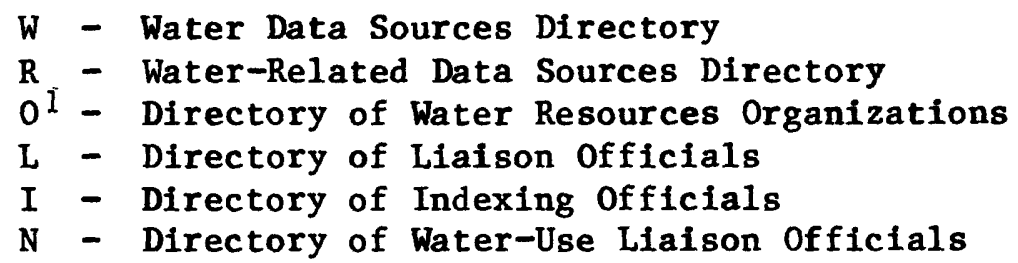

General Description - DIRECTORY TYPE contains a combination of 1 to 10 codes, left-justified, to be used in retrieving specified types of directories. Each code may occur only once in this component. Additional codes will be added by the NAWDEX Program office, as the need arises, to meet future directory needs.

The alphabetic character 0 , not zero, as assigned. 
$\frac{0}{\text { IN SR }}$

MANDATORY N/A

PICTURE N/A

$\frac{\text { OFFICE }}{\text { COMPONENT NAME }}$

KEY N/A $\frac{100}{\text { COMPONENT NUMBER }}$

DATA TYPE SR

Data Values - Information about one or more offices of the organization, including the office's address and telephone number and the areal coverage of the data possessed by the office.

The primary purpose of this schema record is to provide information to NAWDEX users about of fices that can and will supply their data upon request. 
100

$\overline{\text { IN SR }}$

MANDATORY Yes

PICTURE $X(9)$
OFC_CODE

COMPONENT NAME

KEY Yes

LARGEST OR LONGEST VALUE
102

COMPONENT NUMBER

DATA TYPE Char

Data Values - The Office Code is assigned by the NAWDEX Program Office and consists of a 9-character code. The first two characters of the code consists of a two-digit numeric code representing the state or a two-character code representing the country in which the office is located; the next five characters consist of a five-digit numeric code representing the city or place in which the office is located; and the last two characters consist of an arbitrary two-digit sequence number to identify, uniquely, multiple offices within the same city or place. A complete list of country codes is contained in the Federal Information Processing Standards (FIPS) Publication 10-2, dated 1976, entitled "Countries, Dependencies, and Areas of Special Sovereignty"; a complete list of State codes is contained in the Federal Information Processing Standards (FIPS) Publication 5-1, dated 1970, entitled "States and Outlying Areas of the United States"; and a complete list of city and place codes is contained in the Federal Information Processing Standards (FIPS) Publication 55, dated 1978, entitled "Codes for Named Populated Places and Related Entities of the State of the United States."

General Definition - The Office code is assigned by the NAWDEX Program office and is used to retrieve addresses of operating offices from the Water Data Sources Directory data base. The code for an office is unique within an organization but is not necessarily unique across the data base. Its counterpart in the Master Water Data Index data base is component number 17, WDSD OFC CODE. 
100

$\overline{\text { IN SR }}$

MANDATORY

No

PICTURE $\mathrm{X}(15)$
OFC_NAME

COMPONENT NAME

KEY No

LARGEST OR LONGEST VALUE
110

COMPONENT NUMBER

DATA TYPE Char

40 characters

Data Values - The name of the office may contain up to 40 characters.

General Description - This is the official name of the office. If the organization has but a single office, this field may be identical to component 2, ORG_NAME. 
100

$\overline{\text { IN SR }}$

MANDATORY No

PICTURE $\mathrm{X}(15)$
OFC_CONTACT

COMPONENT NAME

KEY No

LARGEST OR LONGEST VALUE
111 COMPONENT NUMBER

DATA TYPE Char 40 characters

Data Values - This component may contain up to 40 characters.

General Description - The office contact is the name, or title, of the person, or office, that should be contacted by a requester for the purpose of obtaining the office's data that are indexed in NAWDEX. 
100

$\overline{\text { IN SR }}$

MANDATORY

No

PICTURE $\mathrm{X}(15)$
OFG_ST /POB

COMPONENT NAME

KEY

No

LARGEST OR LONGEST VALUE
112

COMPONENT NUMBER

DATA TYPE Char

40 characters

Data Values - This component may contain up to 40 characters.

General Description - This is the street address, or post office box number, of the office contact named in component 111 , OFC CONTACT. This is the address to which a requester should send a letter requesting the office's data indexed in NAWDEX. 
100

$\overline{\text { IN SR }}$

MANDATORY

No

PICTURE $X(10)$
OFC_CITY

COMPONENT NAME

KEY

No

LARGEST OR LONGEST VALUE
113

COMPONENT NUMBER

DATA TYPE Char

Data Values - The name of the city, not to exceed 30 characters.

General Description - The city in which the office is located. The city name accompanies the address (component 112) and, therefore, should be the name of the city as it is used for malling purposes. 
100

$\overline{\text { IN SR }}$

MANDATORY

No

PICTURE $X(2)$
OFC_STATE_ABBR

COMPONENT NAME

KEY Yes

LARGEST OR LONGEST VALUE
114

COMPONENT NUMBER

DATA TYPE Char

WY

Data Values - A two-character postal code identifying the State in which the office is Tocated.

General Description - Postal codes are alphabetic State abbreviations recognized by the U.S. Postal Service as part of a mailing address. OFC STATE ABBR should be valued only if the office is located within the United States or one of its territories. If the office is outside the United States, this component is not valued. 
$\frac{100}{\text { IN SR }}$

MANDATORY

No

PICTURE

$X(5)$
OFCLIP

COMPONENT NAME

KEY No

DATA TYPE Char
115

COMPONENT NUMBER

Data Values - This component contains a five-digit number which is the U.S. Postal ZIP code for the address of the organization or a code up to 10 characters in length to define the foreign (non-USA) postal code of the organization.

General Description - The ZIP Code is a five-digit geographic code that identifies areas within the United States and its possessions for purposes of simplifying the distribution of mail by the U.S. Postal Service. The ZIP Code alinements do not necessarily adhere to boundaries of cities, counties, States, or other jurisdictions. For organizations outside the United States and its territories, the foreign postal code, if applicable, will be defined in the format of its local usage. 
$\frac{100}{\text { IN SR }}$

MANDATORY

No

PICTURE $\quad \mathrm{X}(4)$
OFC_COUNTRY_NAME

COMPONENT NAME

KEY

No $\frac{116}{\text { COMPONENT NUMBER }}$

DATA TYPE Char

Data Values - This component contains the name of the country in which the office is located. If the office is in the United States, the abbreviation "USA" is used. For countries other than the United States, the full name of the country is stored in this component.

General Description - The name of the country applies to the country in which the office is physically located. It is the name that is part of the mailing address on correspondence addressed to the office. It bears no relationship to the data holdings of the office. 
100

$\overline{\mathrm{IN} \mathrm{SR}}$

MANDATORY

No

PICTURE $X(12)$
OFC PHONE

COMPONENT NAME

KEY No

DATA TYPE Char
117

COMPONENT NOMBER

LARGEST OR LONGEST VALUE

Data Values - This is the telephone number of the office. If the office is within the United States or one of its territories, the number consists of a three-digit area code, followed by a dash, and followed by the seven digits of the local telephone number. A dash appears between the third and fourth digits of the local number. If the office is outside the United States, whatever format is required is the one used to store the correct telephone number.

General Description - This is the telephone number at which the office and its contact can be reached. 
100

$\overline{\text { IN SR }}$

MANDATORY

YES

PICTURE $\mathbf{X}(10)$
OFC_DIRECTORY_TYPE COMPONENT NAME

KEY Yes

LARGEST OR LONGEST VALUE
118

COMPONENT NUMBER

DATA TYPE Char

Data Values

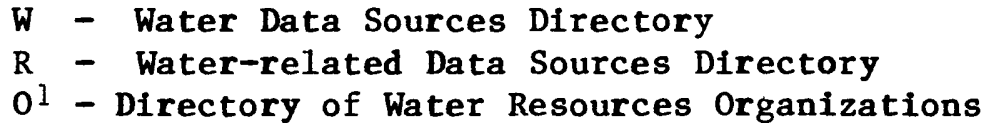

General Description - OFC DIRECTORY TYPE contains a combination of 1 to 10 codes, left-justified, to be used in retrieving specified types of directories. Each code may occur only once in this component. Additional codes will be added by the NAWDEX Program Office, as the need arises, to meet future directory needs.

The alphabetic character 0 , not zero, is assigned. 


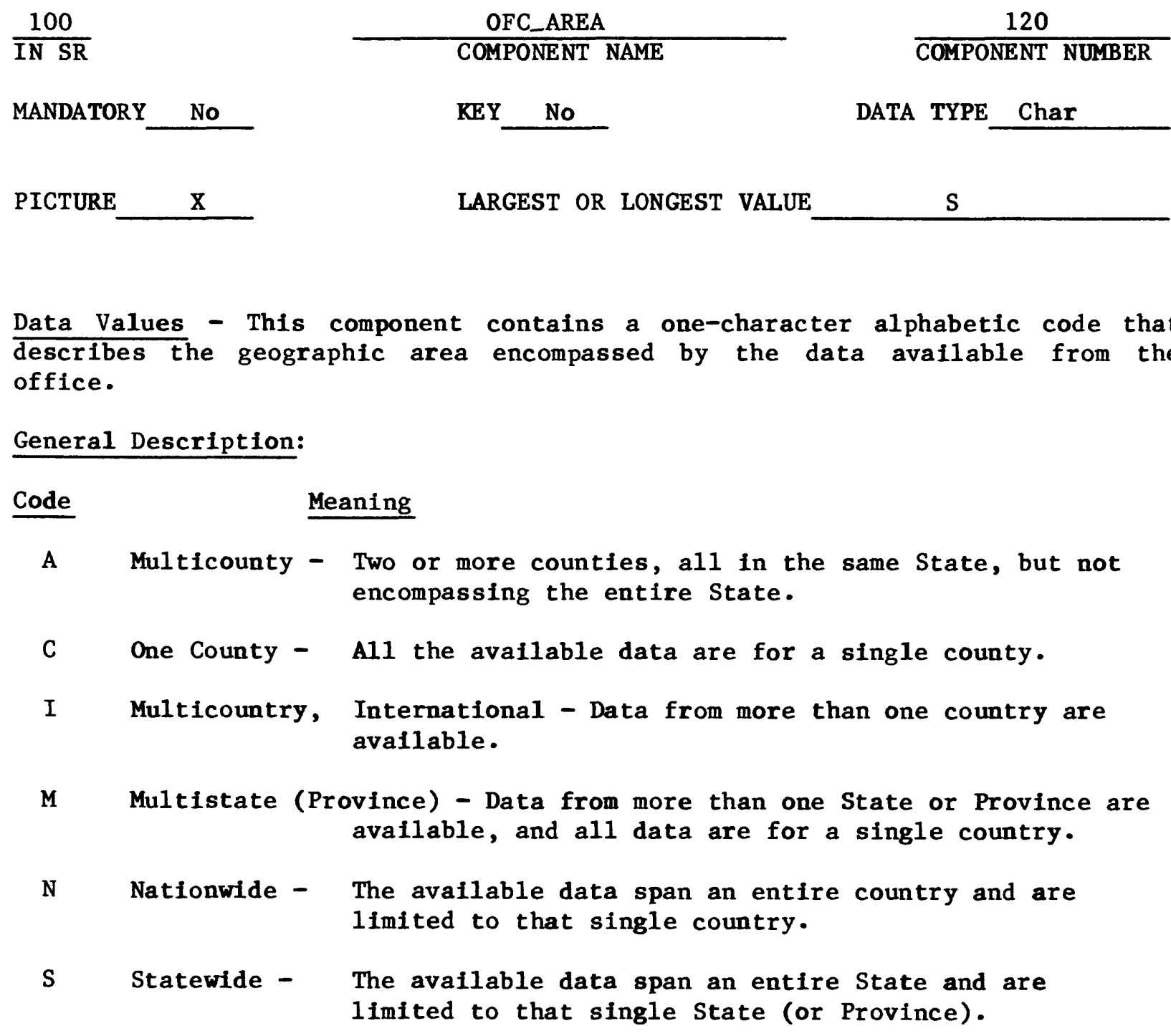


100

$\overline{\text { IN SR }}$

MANDATORY Yes

PICTURE $\mathrm{X}$
OFC_REQUESTS

COMPONENT NAME

KEY

No

LARGEST OR LONGEST VALUE
121

COMPONENT NUMBER

DATA TYPE Char

$\mathrm{Y}$ or $\mathrm{N}$

Data Values - This component is valued with " $Y$ " if the office responds to requests for data, and with " $N$ " if it does not.

General Description - Offices that collect and(or) store water data may or may not choose to furnish that data to those who request it. If the office does respond to requests for its data, then this component is valued with " $Y$ ". This information is furnished to users of NAWDEX so that they can ascertain if the office can be contacted to obtain data.

If the office does not respond to requests for its data, it is still included in the WDSD for administrative purposes, and this component is valued with "N". Frequently offices that do not respond to requests for data furnish their data to one or more organizations that do respond to requests. When this is the case, information about the alternate source of data is contained in schema record number 500 . 
$\frac{100}{\text { IN SR }}$

MANDATORY

No

PICTURE $\mathrm{X}$
OFC_MEDIA

COMPONENT NAME

KEY No
123

COMPONENT NUMBER

DATA TYPE Char

Data Values - This component contains a one-character alphabetic code that describes the type(s) of media used to store the office's hydrologic data.

\section{General Description:}

Code

Meaning

C Computer recognizable - The data are stored on media that can be read by a computer. This might be punched cards, paper tape, magnetic disk, drum, or some similar device.

D Computer and published - Data are stored in both computer recognizable and published form.

E Computer and microform - Data are stored in both computer recognizable and microform formats.

F Computer, published, and microform - Data are stored in computer recognizable, published, and microform formats.

G Published and microform - Data are stored in both published and microform formats.

M Microform - Printed data which are stored in reduced size on roll microfilm, microfiche, aperture cards, or some other type of microfilm.

P Published - The data are available in printed form. 
100

$\overline{\text { IN SR }}$

MANDATORY

No

9

PICTURE
OFC_LAC_FLAG

COMPONENT NAME

KEY Yes LARGEST OR LONGEST VALUE
124

COMPONENT NUMBER

DATA TYPE Integer 1

Data Values - Valued " 1 " if the Office is a NAWDEX Assistance Center. Otherwise, it is not valued.

General Description - The purpose of this component is to identify offices that are Assistance Centers for the NAWDEX program. The service capabilities of NAWDEX are supported by a nationwide network of Assistance Centers. These Centers were established in offices of NAWDEX members to provide local and convenient access to NAWDEX and its services. Most are equipped with computer terminals, thereby providing an extensive telecommunications network for access to the computerized directory and indexes being developed for the NAWDEX program. As the NAWDEX membership increases, additional Centers w111 be added in large population areas and areas of high user interest to provide more optimal access to NAWDEX and its services. A complete directory of Assistance Centers may be obtained from the National Water Data Exchange, U.S. Geological Survey, 421 National Center, Reston, Virginia 22092. 
100

$\overline{\text { IN SR }}$

MANDATORY N/A

PICTURE N N /A
OFC I IAC

COMPONENT NAME

KEY N /A

LARGEST OR LONGEST VALUE
125

COMPONENT NUMBER

DATA TYPE

SR

$\mathrm{N} / \mathrm{A}$

Data Values - The schema record contains the telephone numbers and operating hours of Assistance Centers. 
$\frac{125}{\text { IN SR }}$

MANDATORY Yes

PICTURE $\mathrm{X}(20)$
OFC_LAC_HRS

COMPONENT NAME

KEY

No

DATA TYPE Text

126
COMPONENT NUMBER

LARGEST OR LONGEST VALUE

Data Values - The hours of operation of the Assistance Centers are given in the following manner:

As shown on the following table, the first three characters indicate the time zone, standardized to Greenwich Mean Time; the fourth character is a blank.

United States Time Zone

Atlantic

Eastern

Central

Mountain

Pacific

Yukon

Alaska-Hawail

Bering
Greenwich Standardization

(First Three Characters)

$+04$

$+05$

$+06$

$+07$

$+08$

$+09$

$+10$

$+11$

The following abbreviations are also incorporated: SU for Sunday; $M$ for Monday; $T$ for Tuesday; $W$ for Wednesday; $T H$ for Thursday; $F$ for Friday; $S$ for Saturday.

Thus, the following would be for an office in the Central Time Zone in the U.S.A. which is open from $9 \mathrm{a} . \mathrm{m}$. to $3 \mathrm{p} . \mathrm{m}$. on Monday through Thursday, and

$9 \mathrm{a} \cdot \mathrm{m}$. to $2 \mathrm{p} \cdot \mathrm{m}$. on Friday:

$$
+06 \text { M }- \text { Т Н } 9-3 \text { F } 9-2
$$

General Description - This component contains information about the hours during which someone is available at an Assistance Center to respond to requests for data. 
125

$\overline{\text { IN SR }}$

MANDATORY Yes

PICTURE $\mathrm{X}(12)$
OFC_LAC_PHONE

COMPONENT NAME

KEY No

LARGEST OR LONGEST VALUE
127

COMPONENT NUMBER

DATA TYPE Char

Data Values - This is the telephone number of the Assistance Center. If the office is within the United States or one of its territories, the number consists of a three-digit area code, followed by a dash, followed by seven digits of the local telephone number. A dash appears between the third and fourth digits of the local number. If the office is outside the United States, whatever format is required is the one used.

General Description - This is the telephone number at which the Assistance Center can be reached for the purpose of requesting information from NAWDEX. It may differ from the telephone number in component 117, OFC Phone, because OFC $P H O N E$ is the number to call to request data and index information from NAWDEX. 
100

$\overline{\text { IN SR }}$

MANDATORY N/A

PICTURE N N A
OFC_COMMENTS

COMPONENT NAME

KEY N /A

LARGEST OR LONGEST VALUE
150 COMPONENT NUMBER

DATA TYPE SR

N /A

Data Values - General Information, in textual form, about an office and its data holdings. 
150

$\overline{\text { IN SR }}$

MANDATORY Yes

PICTURE $\quad \mathrm{X}(20)$
OFC_CMNT

COMPONENT NAME

KEY No

LARGEST OR LONGEST VALUE
151

COMPONENT NUMBER

DATA TYPE Text

40 characters

Data Values - Contains textual comments about the office and its data holdings in a textual format.

General Description - The purpose of this component is to provide a means of storing general information about an office and its data holdings. The information may include anything that would potentially be of interest to a user of NAWDEX. 
150

$\overline{\text { IN SR }}$

MANDATORY Yes

PICTURE
OFC_CMNT_SEQ

COMPONENT NAME

KEY

No
152

COMPONENT NUMBER

DATA TYPE Integer

LARGEST OR LONGEST VALUE

99

Data Values - A two-digit number that identifies a comment. The first digit is the sequence number of the comment. The second digit is the sequence number of an individual line of the comment.

Genera1 Description - The comment sequence number has two purposes. One is to distinguish among separate comments. Up to nine comments can be present under any office, and the first digit of the comment sequence number will be valued from one to nine. The second purpose of the sequence number is to permit segmenting long comments into lines of up to 40 characters per 1ine. Each line is numbered from zero to nine so that if a comment has several lines, they will be printed in correct order when sorted by the sequence number in ascending order.

Therefore, the first line of the first comment is numbered "10," the second Iine is numbered "11," etc. The first line of the second comment is "20." 
100

IN SR

MANDATORY N/A

PICTURE

N/A
OFFICE_STORED_DATA

COMPONENT NAME

KEY N/A

LARGEST OR LONGEST VALUE
200

COMPONENT NUMBER

DATA TYPE SR

$\mathrm{N} / \mathrm{A}$

Data Values - Information about the geographic area covered by the data avallable from the office. 
200

$\overline{\text { IN SR }}$

MANDATORY

No

PICTURE $X(2)$
OFC_NON_US_COUNTRY

COMPONENT NAME

KEY Yes

LARGEST OR LONGEST VALUE
201

COMPONENT NUMBER

DATA TYPE Char

Data Values - This component contains a two-character alphabetic FIPS country code, if, and only if, the office has data for sites physically located outside the United States; if the office's data is for sites within the United States, the component will not be valued. Commonly used values are:

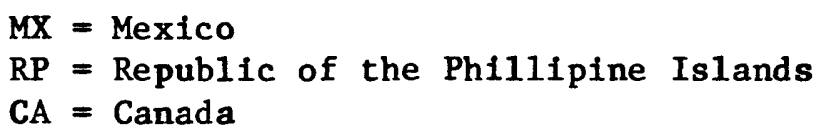

A complete list of country codes is contained in the Federal Information Processing Standards (FIPS) Publication 10-2, dated 1976, entitled "Countries, Dependencies, and Areas of Special Sovereignty."

General Description - The non-United States country code is valued for only those offices that have data from sites that lie outside of the borders of the United States and its outlying areas. It bears no relationship to the location of the office. 
200

$\overline{\text { IN SR }}$

MANDATORY

No
OFC_STATE

COMPONENT NAME

KEY Yes
202

COMPONENT NUMBER

DATA TYPE Integer

PICTURE 9(3)

LARGEST OR LONGEST VALUE

99

Data Values - This component contains a two-digit numeric code representing the State for which the office has data. Numeric codes for foreign installations will also appear, when applicable, as follows:

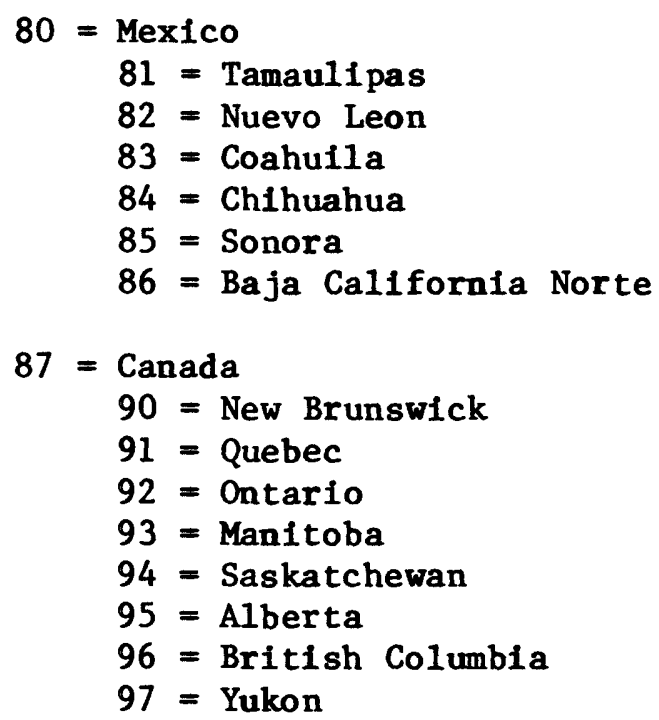

99 = U.S. Foreign Installations - Miscellaneous

General Description - State codes are contained in the Federal Information Processing Standards (FIPS) Publication 5-1, dated June 15, 1970, entitled "States and Outlying Areas of the United States," and temporary codes are assigned by NAWDEX to identify foreign installations. The State code represents the location of a data collection site for which the office has data, not the location of the office itself. 
200

$\overline{\text { IN SR }}$

MANDATORY Yes

PICTURE $\mathrm{X}(10)$
OFFICE_DATA_DIRECTORY TYPE

COMPONENT NAME

KEY Yes

LARGEST OR LONGEST VALUE
218

COMPONENT NUMBER

DATA TYPE Char

10 characters

Data Values

W - Water Data Sources Directory
$R_{\text {- Water-related Data Sources Directory }}$ - Wirectory of Water Resources Organizations
$0^{1}$ - Directorion

General Description - OFFICE DATA DIRECTORY TYPE contains a combination of 1 to 10 codes, left-justified, to be used In retrieving specified types of directories. Each code may occur only once in this component. Additional codes will be added by the NAWDEX Program Office, as the need arises, to meet future directory needs.

The alphabetic character 0 , not zero, is assigned. 
$\frac{200}{\text { IN SR }}$

MANDATORY N/A

PICTURE N /A
OFC_COUNTIES COMPONENT NAME

KEY N /A

LARGEST OR LONGEST VALUE
275

COMPONENT NOMBER

DATA TYPE

SR

N / A

Data Values - Information about the counties for which the office has data. 
$\frac{275}{\text { IN SR }}$

MANDATORY Yes

PICTURE $9(3)$
OFC_COUNTY

COMPONENT NAME

KEY

Yes

LARGEST OR LONGEST VALUE $\frac{276}{\text { COMPONENT NUMBER }}$

DATA TYPE Integer

Data Values - This component contains a three-digit numeric county code for a county for which the office has data. For data from sites outside the United States, this component is not valued.

General Description - This component is valued with a code representing a county in which a data collection site exists, for which the office holds data. The county must be in the State whose code is in component C202, OFC STATE. County codes are contained in the Federal Information Processing Standards (FIPS) Pub1ication 6-3, dated December 15, 1979, entitled "Counties and County Equivalents of the States of the United States and the District of Columbia."

Note: Codes used to value this component include independent city codes for the States of Maryland, Mssouri, Nevada, and Virginia; division codes for the State of Alaska; and county equivalents of Puerto Rico and the Virgin Islands. 
$\frac{0}{\text { IN SR }}$

MANDATORY N /A

PICTURE N N /A
ORGANIZATION_STORED_DATA COMPONENT NAME

KEY N/A

LARGEST OR LONGEST VALUE

N / A
400

COMPONENT NUMBER

DATA TYPE SR

Data Values - Information about the number and types of sites operated by the organization. 
$\frac{400}{\text { IN SR }}$

MANDATORY No

PICTURE
NON_US_COUNTRY

COMPONENT NAME

KEY

Yes $\frac{401}{\text { COMPONENT NUMBER }}$

DATA TYPE

Char

Data Values - This component contains a two-character alphabetic country code, if and only if, the organization operates data collection sites physically located outside the United States. If the organization's data collection sites are within the United States, the component is not valued. Commonly used values are:

$$
\begin{aligned}
& M X=\text { Mexico } \\
& R P=\text { Republic of the Phillipine Islands } \\
& C A=\text { Canada }
\end{aligned}
$$

A complete list of country codes is contained in the Federal Information Processing Standards (FIPS) Publication 10-2, dated 1976, entitled "Countries, Dependencles, and Areas of Special Sovereignty."

General Description - The non-United States country code is valued for only those organizations that operate data collection sites that lie outside of the borders of the United States and its outlying areas. It bears no relationship to the location of the organization. 
400

$\overline{\text { IN SR }}$

MANDATORY No

PICTURE
STATE

COMPONENT NAME

KEY Yes

DATA TYPE Integer

Data Values - This component contains a two-digit numeric code representing the State in which the organization operates data collection sites. Numeric codes for foreign countries will also appear, when applicable, as follows:

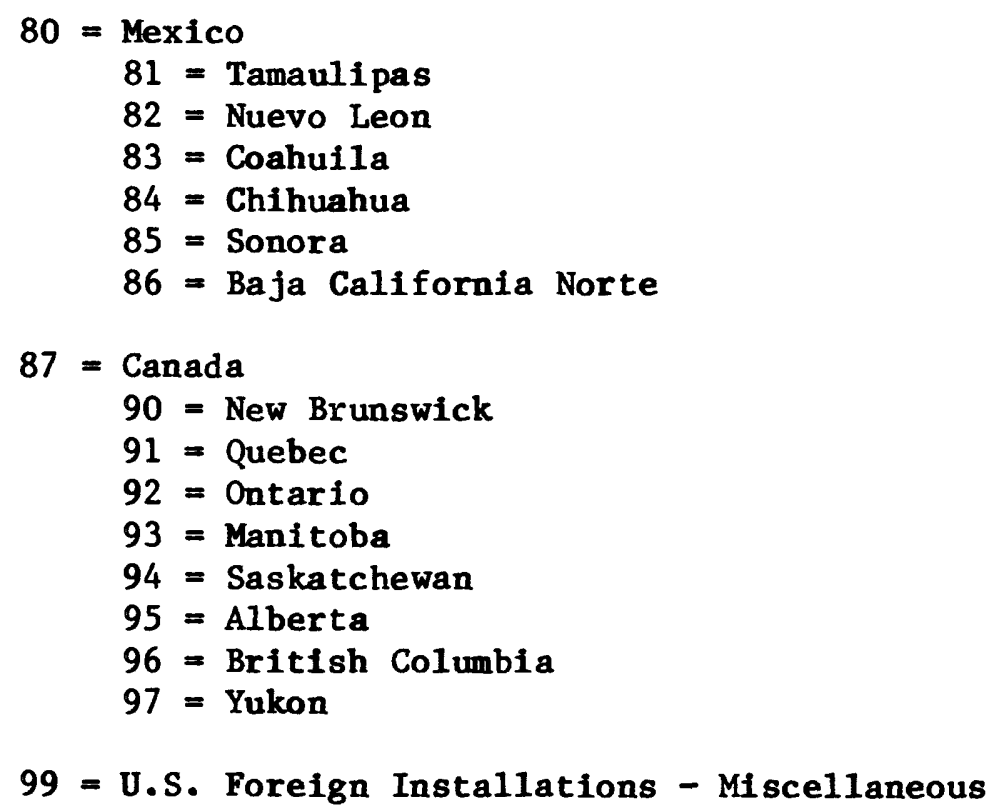

A complete list of State codes is contained in the Federal Information Processing Standards (FIPS) Publication 5-1, dated June 15, 1970, entitled "States and Out1ying Areas of the United States."

General Description - The STATE component is valued for those States in which there are sites for which the organization has data. It bears no relationship to the location of the organization. 
400

$\overline{\text { IN SR }}$

MANDATORY No

KEY Yes
403

COMPONENT NUMBER

DATA TYPE Integer

PICTURE 9(7)

LARGEST OR LONGEST VALUE

$9,999,999$

Data Values - This is the total number of surface-water-quality sites, located In the State identified by component 402 or the country identified by component 401 , which the organization operates.

General Description - The total includes surface-water sites at which one or more water-quality parameters are, or have been, collected. It includes both active and inactive sites and it makes no difference whether or not the data are supplied by the organization upon request. Sites included in the total are only those that are operated by the organization in the State identified by component 402 or the country identified by component 401 . Water-quality parameters include physical, chemical, sediment, or biological characteristics of water. 
400

IN SR

MANDATORY

No

PICTURE 9(7)
SW_ONTY

COMPONENT NAME

KEY Yes

LARGEST OR LONGEST VALUE $\frac{404}{\text { COMPONENT NUMBER }}$

DATA TYPE Integer

Data Values - This is the total number of surface-water-quantity sites, located in the State identified by component 402 or the country identified by component 401 , which the organization operates.

General Description - The total includes surface-water sites at which one or more water-quantity parameters are, or have been, collected. It includes both active and inactive sites and it makes no difference whether or not the data are supplied by the organization upon request. Sites included in the total are only those that are operated by the organization in the State identified by component 402 or the country identified by component 401 . Surface-waterquantity parameters include such items as streamflow, peak flow, low flow, peak stage, low stage, reservoir content, and change in reservoir content. 
400

$\overline{\text { IN SR }}$

MANDATORY

No

PICTURE 9(7)
GW_QLTY

COMPONENT NAME

KEY Yes
405

COMPONENT NUMBER

DATA TYPE Integer

Data Values - This is the total number of ground-water-quality sites, located In the State identified by component 402 or the country identified by component 401 , which the organization operates.

General Description - The total includes ground-water sites at which one or more water quality parameters are, or have been, collected. It includes both active and inactive sites and it makes no difference whether or not the data are supplied by the organization upon request. Sites included in the total are only those that are operated by the organization in the State identified by component 402 or the country identified by component 401 . Water quality parameters include physical, chemical, or biological characteristics of water. 
400

$\overline{\text { IN SR }}$

MANDATORY

No

PICTURE 9(7)
GLLLVL

COMPONENT NAME

KEY Yes

LARGEST OR LONGEST VALUE
406

COMPONENT NUMBER

DATA TYPE Integer

$9,999,999$

Data Values - This is the total number of data-monitoring sites the organization operates, at which water-level measurements are made in the State identified by component 402 or the country identified by component 401 .

General Description - The total includes ground-water sites at which water level measurements are, or have been, collected. It includes both active and inactive sites and it makes no difference whether or not the data are supplied by the organization upon request. Sites included in the total are only those that are operated by the organization in the State identified by component 402 or the country identified by component 401 . 
$\frac{400}{I N S R}$

MANDATORY

No

PICTURE $9(7)$
GW_PUMP

COMPONENT NAME

KEY Yes

LARGEST OR LONGEST VALUE
407

COMPONENT NUMBER

DATA TYPE Integer

Data Values - This is the total number of data-monitoring sites, at which there is ground-water pumpage, located in the State identified by component 402 or the country identified by component 401, which the organization operates.

General Description - The total includes ground-water sites at which pumpage measurements are, or have been, collected. It includes both active and inactive sites and it makes no difference whether or not the data are supplied by the organization upon request. Sites included in the total are only those that are operated by the organization in the State identified by component 402 or the country identified by component 401 . 
$\frac{400}{\operatorname{InR}}$

$\overline{\text { IN SR }}$

MANDATORY

No

PICTURE $9(7)$
GLGC

COMPONENT NAME

KEY Yes

LARGEST OR LONGEST VALUE
408

COMPONENT NUMBER

DATA TYPE Integer

Data Values - This is the total number of ground-water sites with geologic descriptions available, located in the state identified by component 402 or the country identified by component 401 , which the organization operates.

General Description - The total includes ground-water sites for which there is information describing the geology in wich the site is located. This includes descriptions of the surficial geology and other information such as stratigraphic or lithologic logs. It includes both active and inactive sites and it makes no difference whether or not the information is supplied by the organization upon request. Sites included in the total are only those that are operated by the organization in the state identified by component 402 or the country identified by component 401. 
400

$\overline{\mathrm{IN} \mathrm{SR}}$

MANDATORY NO

PICTURE 9(7)
WATER USE

COMPONENT NAME
409

COMPONENT NUMBER

KEY YES DATA TYPE Integer

LARGEST OR LONGEST VALUE 9,999,999

Data Values - This is the total number of sites or locations at which water-use data are being collected or monitored by the organization in the State identified by component 402 or the country identified by component 401 .

General Description - The total includes all sites or locations at which wateruse data are, or have been, collected or monitored. It includes both active and inactive sites or locations and it makes no difference whether or not the data are supplied by the organization upon request. Sites or locations included in the total are only those that are operated by the organization in the State identified by component 402 or the country identified by component 401. Water-use data includes a11 data and information collected about the use of water, both withdrawals and returns, for agriculture, industry, municipal water supplies, domestic use, energy production and development, mining, and a variety of other purposes. 
400

IN SR

MANDATORY NO

PICTURE $9(7)$
MET_DATA

COMPONENT NAME

KEY

Yes

LARGEST OR LONGEST VALUE
410

COMPONENT NUMBER

DATA TYPE Integer

$9,999,999$

Data Values - This is the total number of sites at which meteorological data are measured or monitored by the orgainization in the state idenţified by component 402 or the country identified in component 401 .

General Description - The total includes all sites at which meteorological data are, or have been, collected or monitored. It includes both active and inactive sites and it makes no difference whether or not the data are supplied by the organization upon request. Sites included in the total are only those that are operated by the organization in the State identified by component 402 or the country identified in component 401. Meteorological data include measurements of precipitation, snow accumulations, wind direction and velocity, temperature, relative humidity, and others. 
400

IN SR

MANDATORY Yes

PICTURE $X(10)$
DATA_DICTIONARY_TYPE

COMPONENT NAME

KEY Yes

LARGEST OR LONGEST VALUE
418

COMPONENT NUMBER

DATA TYPE

Char

Data Values

$$
\begin{aligned}
& \text { W - Water Data Sources Directory } \\
& \text { R - Water-related Data Sources Directory } \\
& 0^{1} \text { - Directory of Water Resources Organizations }
\end{aligned}
$$

General Description - DATA DIRECTORY TYPE contains a combination of 1 to 10 codes, left-justified, to be used in retrieving specified types of directories. Each code may occur only once in this component. Additional codes will be added by the NAWDEX Program Office, as the need arises, to meet future directory needs.

The alphabetic character 0 , not zero, is assigned. 
400

IN SR

MANDATORY N/A

PICTURE N/A
COUNTIES

COMPONENT NAME

KEY N/A

LARGEST OR LONGEST VALUE
475

COMPONENT NUMBER

DATA TYPE $\quad$ SR

$\mathrm{N} / \mathrm{A}$

Data Values - Identifies the counties in which the organization operates data collection sites. 
$\frac{475}{\text { IN SR }}$

MANDATORY Yes

PICTURE $9(3)$
COUNTY

COMPONENT NAME

KEY Yes
476

COMPONENT NUMBER

DATA TYPE Integer

LARGEST OR LONGEST VALUE 840

Data Values - This component contains a three-digit numeric code for a county in which the organization operates one or more data collection sites. For sites operated outside the United States, there will be no occurrences of the COUNTIES schema record.

General Description - This component is valued for those counties in which there are one or more data collection sites operated by the organization. The counties must be in the State identified in component 402, STATE. A complete 1ist of county codes is contained in the Federal Information Processing Standards (FIPS) Publication 6-3, dated December 15, 1979, entitled "Counties and County Equivalents of the States of the United States and the District of Columbia."

Note: Codes used to value this component include independent city codes for the States of Maryland, Missouri, Nevada, and Virginia; division codes for the State of Alaska; and county equivalent codes for American Samoa, Guam, Puerto Rico, and the Virgin Islands. 
$\frac{0}{\text { IN SR }}$

MANDATORY N /A

PICTURE N/A
OTHER_SOURCE

COMPONENT NAME

KEY N/A

LARGEST OR LONGEST VALUE $\frac{500}{\text { COMPONENT NUMBER }}$

DATA TYPE SR

Data Values - Information about other sources of the organization's data. If another organization stores, in part or in whole, data avallable from the organization named in component ORG NAME, and will respond to requests for the data, that organization is an "other source." 
500

$\overline{\text { IN SR }}$

MANDATORY Yes

PICTURE

$\mathrm{X}$
OT_SRC_ALT /PRF

COMPONENT NAME

KEY

No
501

COMPONENT NUMBER

DATA TYPE

Char

Data Values - Contains either an " $A$ " or a " $P$ " depending upon whether the organization is an alternate source or a preferred source, respectively.

General Description - A distinction is made between an alternate source, an "other source" which can be contacted instead of the organization that collected the data, and a preferred data source, an "other source" which should be contacted instead of the collector organization. A collector organization that does not have the capability to respond to requests for data may designate another organization as a preferred source. If the collector organization will respond to requests for its data, and its data is also available from another organization, that other organization may be designated as an alternate source.

All data stored by the collector organization may not be available from the "other source" organization. Component 522, OT SRC DATA, tells what kinds of data are available from the "other source" orgañization, and any further qualifications can be explained in comment form in component 551, OT_SRC_CMNT. 
500

$\overline{\text { IN SR }}$

MANDATORY Yes

PICTURE

$X(5)$
OT_SRC_AGCY

COMPONENT NAME

KEY Yes

LARGEST OR LONGEST VALUE
502

COMPONENT NUMBER

DATA TYPE Char

Data Values - This is the NAWDEX agency code for the "other source" organization. The NAWDEX agency code varies in length from three to five characters. For Federal organizations it is US followed by a two- or three-character meaningful abbreviation of the organization name. Values for non-Federal organizations whose activities are contained within a given State boundary will have a two-character alphabetic State code followed by a NAWDEX assigned sequence number. Values for non-Federal organizations having activities at the multistate or national level have a three- to fivecharacter meaningful abbreviation of the organization name (the characters US will not appear in the first two character positions). Alphabetic State codes are contained in the Federal Information Processing standards (FIPS) Publication 5-1, dated June 15, 1970, entitled "States and Outlying Areas of the United States." NAWDEX agency codes are presented in the publication entitled "Identification Codes for Organizations Listed in Computerized Data Systems of the U.S. Geological Survey," which may be obtained from the National Water Data Exchange, U.S. Geological Survey, 421 National Center, Reston, Virginia 22092.

General Description - The NAWDEX agency code is assigned by the NAWDEX Program office and is the unique identifier for the particlpating Federal and non-Federal organizations that actively collect and store water data. Non-Federal organizations include State, county, and municipal agencies, as well as intergovernmental compacts, private organizations, universities, and any local organizations at other than county or municipal level. 
500

IN SR

MANDATORY Yes

PICTURE $\mathrm{X}(23)$

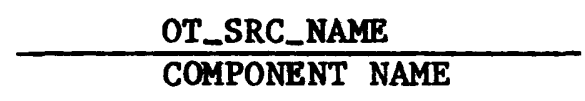

KEY No

LARGEST OR LONGEST VALUE $\frac{510}{\text { COMPONENT NUMBER }}$

DATA TYPE Char

40 characters

Data Values - The name of the organization may contain up to 40 characters.

General Description - This is the official name of the organization. 
500

$\overline{\text { IN SR }}$

MANDATORY

No

PICTURE $X(15)$
OT_SRC_CONTACT

COMPONENT NAME

KEY No

LARGEST OR LONGEST VALUE
511

COMPONENT NUMBER

DATA TYPE Char

Data Values - This component may contain up to 40 characters.

General Description - The contact is the name, or title, of the person, or organization, that should be contacted by a requester for the purpose of obtaining the organization's data that are indexed in NAWDEX. 
$\frac{500}{\text { IN SR }}$

MANDATORY

No

PICTURE $\mathbf{X}(15)$
OT_SRC_ST /POB

COMPONENT NAME

KEY No

LARGEST OR LONGEST VALUE
512

COMPONENT NUMBER

DATA TYPE Char

Data Values - This component may contain up to 40 characters.

General Description - This is the street address or post office box number of the contact named in component 511, OT SRC CONTACT. It is the address to which a requester should send a letter asking for the organization's data indexed in NAWDEX. 
500

$\overline{\text { IN SR }}$

MANDATORY

No

o

PICTURE $\mathbf{X}(\mathbf{1 0 )}$
OT_SRC_CITY

COMPONENT NAME

KEY No

DATA TYPE Char

513

COMPONENT NUMBER

30 characters

Data Values - The name of a city, not to exceed 30 characters.

General Description - The city in which the organization is located. The city name accompanies the address (component 512) and, therefore, should be the name of the city as it is used for malling purposes. 
500

IN SR

MANDATORY

No

PICTURE $\quad X X$
OT_SRC_STATE_ABBR

COMPONENT NAME

KEY No

LARGEST OR LONGEST VALUE
514

COMPONENT NUMBER

DATA TYPE Char

WY

Data Values - A two-character postal code Identifying the State in which the organization is located.

General Description - Postal codes are alphabetic State abbreviations recognized by the J.S. Postal Service as part of a malling address. OT SRC STATE ABBR should be valued only if the organization is located within the United States or one of its territories. If the organization is outside the United States, this component is not valued. 
500

$\overline{\text { IN SR }}$

MANDATORY

No

PICTURE $\quad X(5)$
OT_SRC_ZIP

COMPONENT NAME

KEY

No

LARGEST OR LONGEST VALUE
515

COMPONENT NUMBER

DATA TYPE Char

Data Values - This component contains a five-digit number which is the U.S. Postal ZIP code for the address of the organization or a code up to 10 characters in length to define the foreign (non-USA) postal code of the organization.

General Description - ZIP Code is a five-digit geographic code that identifies areas within the United States and its possessions for purposes of simplifying the distribution of mall by the U.S. Postal Service. The ZIP Code alinements do not necessarily adhere to boundaries of cities, counties, States, or other jurisdictions. For organizations outside the United States and its territories, the forelgn postal code, if applicable, will be defined in the format of its local usage. 
500

$\overline{\text { IN SR }}$

MANDATORY

No

PICTURE $\mathrm{x}(4)$
OT_SRC_COUNTRY_NAME

COMPONENT NAME

KEY

No $\frac{516}{\text { COMPONENT NUMBER }}$

DATA TYPE Char

Data Values - This component contains the name of the country in which the organization is located. If the organization is in the United States, the abbreviation "USA" is used. For non-United-States countries, the full name of the country is stored in this component.

General Description - The name of the country applies to the country in which the organization is physically located. It is the name that would be part of a malling address on correspondence addressed to the organization. It bears no relationship to the data holdings of the organization. 
500

$\overline{\text { IN SR }}$

MANDATORY No

PICTURE $X(12)$
OT_SRC_PHONE

COMPONENT NAME

KEY No

LARGEST OR LONGEST VALUE

999-999-9999

Data Values - This is the telephone number of the contact named in component 511 , OT_SRC_CONTACT. If the office is within the United States or one of its territories, the number consists of a three-digit area code, followed by a dash, and followed by the seven digits of the local telephone number. A dash appears between. the third and fourth digits of the local number. If the office is outside the United States, whatever format is required is the one used to store the correct telephone number.

General Description - This is the telephone number at which the office and its contact can be reached. 
500

$\overline{\text { IN SR }}$

MANDATORY

Yes

PICTURE $\mathbf{X}(10)$
OT_SRC_DIRECTORY_TYPE

COMPONENT NAME

KEY

Yes

DATA TYPE Char

LARGEST OR LONGEST VALUE

Data Values

W - Water Data Sources Directory

R - Water-related Data Sources Directory

$0^{l}$ - Directory of Water Resources Organizations

General Description - OT SRC DIRECTORY TYPE contains a combination of 1 to 10 codes, left-justified, to be used in retrieving specified types of directories. Each code may occur only once in this component. Additional codes will be added by the NAWDEX Program Office, as the need arises, to meet future directory needs.

The alphabetic character 0 , not zero, is assigned. 
500

$\overline{\text { IN SR }}$

MANDATORY Yes

PICTURE $\quad \mathbf{X}(4)$
OT_SRC_DATA

COMPONENT NAME

KEY

No

LARGEST OR LONGEST VALUE

Data Values - This component contains one or more alphabetic codes indicating what kinds of data from the collector organization are available from the "other source" organization. From one to six codes can be used.

General Description:

Code $\quad \underline{\text { Meaning }}$

D Geologic Descriptions - Information describing the geology of the area around data collection sites is available.

G Ground Water Quality - Water quality data from ground-water sites are available.

L Ground Water Leve1 - Water-leve1 measurements from ground-water sites are avallable.

P Ground Water Pumpage - Pumpage measurements (drawdown, volume) from ground-water sites are available.

Q Surface Water Quantity - Water-quantity data from surface-water sites are avallable.

S Surface Water Quality Stations - Water-quality data from surface-water sites are available. 
$\frac{500}{\text { IN SR }}$

MANDATORY

No

$\mathrm{X}$
OT_SRC_MEDIA

COMPONENT NAME

KEY

No

LARGEST OR LONGEST VALUE
523

COMPONENT NUMBER

DATA TYPE Char

P

Data Values - This component contains a one-character alphabetic code that describes the type(s) of media used to store the organization's hydrologic data.

\section{General Description:}

Code

Meaning

C Computer recognizable - The data are stored on media that can be read by a computer. This might be punched cards, paper tape, magnetic tape, magnetic disk, drum, or some similar device.

D Computer and published - Data are stored in both computer recognizable and pub1ished form.

E Computer and microform - Data are stored in both computer recognizable and microform formats.

F Computer, pub1ished, and microform - Data are stored in computer recognizable, published, and microform formats.

G Published and microform - Data are stored in both published and microform formats.

M Microform - Printed data which are stored in reduced size on roll microfilm, microfiche, aperture cards, or some other type of microfilm.

P Published - The data are available in printed form. 
$\frac{500}{S R}$

MANDATORY

$\mathrm{N} / \mathrm{A}$

$\mathrm{N} / \mathrm{A}$

PICTURE
OT_SRC_COMMENTS COMPONENT NAME

KEY N /A
DATA TYPE SR

COMPONENT NUMBER

LARGEST OR LONGEST VALUE

$\mathrm{N} / \mathrm{A}$

Data Values - General Information, in textual form, about an "other source" organization and its data holdings. 
$\frac{550}{\text { IN SR }}$

MANDATORY

Yes

PICTURE $\quad X(20)$

PICTURE
OT_SRC_CMNT

COMPONENT NAME

KEY

No

LARGEST OR LONGEST VALUE
551

COMPONENT NUMBER

DATA TYPE

Text

Data Values - Contains textual comments about the "other source" organization and its data holdings in a textual format.

General Description - The purpose of this element is to provide a means of storing general information about an "other source" organization and its data holdings. The information may include anything that would potentially be of interest to a user of NAWDEX. 
550

IN SR

MANDATORY

Yes

PICTURE
OT_SRC_CMNT_SEQ

COMPONENT NAME

KEY

No
552

COMPONENT NUMBER

DATA TYPE Integer

Data Values - A two-digit number that identifies a comment. The first digit is the sequence number of the comment. The second digit is the sequence number of an individual line of the comment.

General Description - The comment sequence number has two purposes. One is to distinguish among separate comments. Up to nine comments can be present under any "other source" organization, and the first digit of the comment sequence number will be valued from one to nine. The second purpose of the sequence number is to permit segmenting long comments into lines of up to 40 characters per 1ine. Each line is numbered from zero to nine so that if a comment has several lines, they will be printed in ascending order when sorted by the sequence number.

Therefore, the first line of the first comment is numbered "10," the second IIne is numbered "11," etc. The first line of the second comment is "20." 
$\frac{0}{\text { IN SR }}$

MANDATORY N $/ A$ $\mathrm{N} / \mathrm{A}$
MWDI_LIASON_OFFICIALS

COMPONENT NAME

KEY N/A

LARGEST OR LONGEST VALUE
1000

COMPONENT NUMBER

DATA TYPE SR N/A

Data Values - Information about individuals within the organization that should be consulted on water-data aquisition, coordination, and indexing activities. Information may also be provided about individuals that serve as liaison officials in other water-related matters as the need arises. 
1000

$\overline{\text { IN SR }}$

MANDATORY

Yes

$X(9)$

PICTUR
LIASON_OFC_CODE

COMPONENT NAME

KEY

No
1002

COMPONENT NUMBER

DATA TYPE Char

LARGEST OR LONGEST VALUE 9 characters

Data Values - The Liaison Office Code is assigned by the NAWDEX Program Office and consists of a 9-character code. The first two characters of the code consists of a two-digit numeric code representing the state or a twocharacter code representing the country in which the office is located; the next five characters consist of a five-digit numeric code representing the city or place in which the office is located; and the next two characters consist of an arbitrary two-digit sequence number to uniquely identify multiple offices within the same city or place. A complete list of country codes is contained in the Federal Information Processing Standards (FIPS) Publication 10-2, dated 1976, entitled "Countries, Dependencies, and Areas of Special Sovereignty"; a complete 1ist of State codes is contained in the Federal Information Processing Standards (FIPS) Publication 5-1, dated 1970, entitled "States and Outlying areas of the United States"; and a complete 1ist of city and place codes is contained in the Federal Information Processing Standards (FIPS) Publication 55, dated 1978, entitled "Codes for Named Populated Places and Related Entities of the States of the United States."

General Description - The Liaison office Code is assigned by the NAWDEX Office and is used to retrieve addresses of liaison offices from the Water Data Sources Directory data base. The code for an office is unique within an organization but is not necessarily unique across the data bases. 
1000

$\overline{\text { IN SR }}$

MANDATORY No

PICTURE X(15)
LIASON OFFICE TITLE

COMPONENT NAME

KEY No

LARGEST OR LONGEST VALUE
1009

COMPONENT NUMBER

DATA TYPE Char

40 characters

Data Values - This component may contain up to 40 characters.

General Description - This is the official name of the office in which the ilaison official resides, the title of the liaison official, or a combination of these, as appropriate. 
1000

$\overline{\text { IN SR }}$

MANDATORY

No

PICTURE $\quad X(15)$
LIASON OFC NAME

COMPONENT NAME

KEY No

LARGEST OR LONGEST VALUE
1010

COMPONENT NUMBER

DATA TYPE Char

40 characters

Data Values - The name of the office may contain up to 40 characters.

General Description - This is the official name of the office within the organization in which the liaison official resides. 
1000

$\overline{\text { IN SR }}$

MANDATORY No

PICTURE $\mathrm{X}(15)$
LIASON_CONTACT

COMPONENT NAME

KEY No

LARGEST OR LONGEST VALUE
1011

COMPONENT NUMBER

DATA TYPE

Char

Data Values - This component may contain up to 40 characters.

General Description - The contact is the name of the person within the organization who should be contacted on matters related to water-data acquisition, coordination, and indexing, or other matters as defined by component 1018, LIAISON_DIRECTORY_TYPE. 
1000

IN SR

MANDATORY

No

PICTURE $\quad X(15)$
LIASON_ST /POB

COMPONENT NAME

KEY No

LARGEST OR LONGEST VALUE
1012

COMPONENT NUMBER

DATA TYPE Char

Data Values - This component may contain up to 40 characters.

General Description - This is the street address or post office box number of the office of the liaison official. 
1000

IN SR

MANDATORY

No

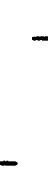

LIASON_CITY

COMPONENT NAME

KEY

No
1013

COMPONENT NUMBER

DATA TYPE Char

PICTURE $\quad X(10)$

LARGEST OR LONGEST VALUE

30 characters

Data Values - The name of a city, not to exceed 30 characters.

General Description - The city in which the liaison office is located. The city name accompanies the address (component 1012) and, therefore, should be the name of the city as it is used for malling purposes. 
1000

$\overline{\text { IN SR }}$

MANDATORY

No

PICTURE $\mathbf{X X}$
LIASON_STATE_ABBR

COMPONENT NAME

KEY Yes
1014

COMPONENT NUMBER

DATA TYPE Char

WY

Data Values - A two-character postal code abbreviation that identifies the State in which the liaison office is located.

General Description - Postal codes are alphabetic State abbreviations recognized by the U.S. Postal Service as part of a malling address. LIASON STATE ABBR should be valued only if the office is located within the United States or one of its territor $\overline{1 e s .}$ If the office is outside the United States, this component is not valued. 
1000

$\overline{\text { IN SR }}$

MANDATORY

No

PICTURE

$X(5)$
LIASON ZIP

COMPONENT NAME

KEY NO

DATA TYPE
1015

COMPONENT NUMBER

Data Values - This component contains a five-digit number which is the U.S. Postal ZIP code for the address of the office, or a code up to 10 characters in length to define the foreign (non-USA) postal code of the organization.

Genera1 Description - The ZIP Code is a five-digit geographic code that identifies areas within the United States and its possessions for purposes of simplifying the distribution of mail by the U.S. Postal Service. The ZIP Code alinements do not necessarily adhere to boundaries of cities, States, or other jurisdictions. For organizations outside the United States and its territories, the foreign postal code, if applicable, will be defined in the format of its local usage. 
1000

$\overline{\text { IN SR }}$

MANDATORY

No

PICTURE

$X(4)$
LIASON_COUNTRY_NAME

COMPONENT NAME

KEY

No

DATA TYPE Char

1016

COMPONENT NUMBER

Data Values - This component contains the name of the country in which the iiaison office is located. If the office is in the United States, the abbreviation "USA" is used. For non-United States countries, the full name of the country is stored in this component.

General Description - The name of the country applies to the country in which the office is physically located. It is the name that is part of the mailing address on correspondence addressed to the office. 
1000

IN SR

MANDATORY

No

PICTURE

$\mathrm{X}(12)$
LIASON_PHONE

COMPONENT NAME

KEY

No

DATA TYPE

Char
1017

COMPONENT NUMBER

LARGEST OR LONGEST VALUE 999-999-9999

Data Values - This is the telephone number of the liaison office. If the office is within the United States or one of its territories, the number consists of a three-digit area code, followed by a dash, followed by the seven digits of the local telephone number. A dash appears between the third and fourth digits of the local number. If the office is outside the United States, whatever format is required is the one used.

General Description - This is the telephone number at which the 1laison official can be reached. 
1018

$\overline{\text { IN SR }}$

MANDATORY Yes

KEY Yes

DATA TYPE

Char

PICTURE $X(10)$

LARGEST OR LONGEST VALUE 10 characters

Data Values

L - Directory of Lialson Offictals

I - Directory of Indexing Officials

N - Directory of Water-Use Liaison Officials

General Description - LIAISON DIRECTORY TYPE contains a combination of 1 to 10 codes, left-justified, to be used in retrieving specified types of directories. Each code may occur only once in this component. Additional codes will be added by the NAWDEX Program Office, as the need arises, to meet future directory needs. 
1000

$\overline{\text { IN SR }}$

MANDATORY N/A

PICTURE N/A
LIASON_STATES

COMPONENT NAME

KEY N/A

LARGEST OR LONGEST VALUE

DATA TYPE
1020

COMPONENT NUMBER

SR

N /A

Data Values - Information about the geographic areas in which the liaison official identified in component 1011, LIASON CONTACT, has jurisdiction. 
1020

IN SR

MANDATORY Yes

PICTURE 9(3)
LIASON_STATE

COMPONENT NAME

KEY Yes

LARGEST OR LONGEST VALUE
1021

COMPONENT NUMBER

DATA TYPE Integer

Data Values - This component contains a two-digit numeric code representing a State within which the liaison official identified in component 1011, LIASON_CONTACT, has jurisdiction.

General Description - State codes are contained in the Federal Information Processing Standards (FIPS) Publication 5-1, dated June 15, 1970, entitled "States and Out1ying Areas of the United States." 
1020

IN SR

MANDATORY No

PICTURE $\mathbf{X}(2)$
LIASON_NON_US_COUNTRY

COMPONENT NAME

KEY No
1022

COMPONENT NUMBER

DATA TYPE Char

Data Values - This component contains a two-character code representing a country other than the United States within which the liaison official identified in component 1011, LIASON_CONTACT, has jurisdiction.

General Description - The liaison non-United States country codes are valued only if the liaison official has jurisdiction outside the United States. Country codes are contained in the Federal Information Processing Standards (FIPS) Publication 10-2, dated 1976, entitled "Countries, Dependencies, and Areas of Special Sovereignty." 
1000

$\overline{\text { IN SR }}$

MANDATORY N/A

PICTURE N/A
LIASON_COMMENTS COMPONENT NAME

KEY N /A

IARGEST OR LONGEST VALUE
1050

COMPONENT NUMBER

DATA TYPE SR

Data Values

- General Information, in textual form, about the liaison activities. 
1050

$\overline{\text { IN SR }}$

MANDATORY Yes

PICTURE $\mathrm{X}(20)$
LIASON_CMNT

COMPONENT NAME

KEY No

DATA TYPE
1051

COMPONENT NUMBER

Text

40 characters

Data Values - Contains textual comments about the liaison office and its data holdings in a textual format.

General Description - The purpose of this component is to provide a means of storing general information about a liaison office and its data holdings. The information may include anything that would potentially be of interest to a user of NAWDEX. 
1050

IN SR

MANDATORY Yes

PICTURE 99
LIASON_CMNT_SEQ.

COMPONENT NAME

REY No

DATA TYPE Integer
1052

COMPONENT NUMBER

LARGEST OR LONGEST VALUE 99

Data Value A two-digit number that identifies a comment. The first digit is the sequence number of the comment. The second digit is the sequence number of an individual line of the comment.

General Description - The comment sequence number has two purposes. One is to distinguish among separate comments. Up to nine comments can be present under any liaison office, and the first digit of the comment sequence number will be valued from one to nine. The second purpose of the sequence number is to permit segmenting long comments into lines of up to 40 characters per 1 ine. Each line is numbered from zero to nine so that if a comment has several lines, they will be printed in ascending order when sorted by the sequence number.

Therefore, the first line of the first comment is numbered "10," the second line is numbered "11," etc. The first line of the second comment is "20." 
$\frac{0}{\text { IN SR }}$

MANDATORY N/A

PICTURE N/A

$\frac{\text { MWDI_DATA }}{\text { COMPONENT NAME }}$

KEY N/A

LARGEST OR LONGEST VALUE
1500

COMPONENT NUMBER

DATA TYPE SR

Data Values - Information on the total number of an organization s data collection sites about which data are stored in the Master Water Data Index (MWDI) data base of the National Water Data Exchange (NAWDEX). 
1500

$\overline{\text { IN SR }}$

MANDATORY No

PICTURE $\mathrm{X}(2)$
MWDI_NON_US_COUNTRY

COMPONENT NAME

KEY Yes
1501

COMPONENT NUMBER

DATA TYPE

Char

LARGEST OR LONGEST VALUE 2 characters

Data Values - This component contains a two-character alphabetic country code if the organization has sites in the Master Water Data Index (MWDI) data base that are physically located outside the United States. If the organization's sites are within the United States, this component is not valued. Commonly used values are:

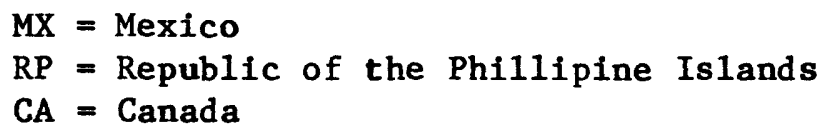

A complete list of country codes is contained in the Federal Information Processing Standards (FIPS) Publication 10-2, dated 1976, entitled "Countries, Dependencies, and Areas of Special Sovereignty."

General Description - This component is valued only if the organization operates sites outside the boundaries of the United States and its territories and if one or more of those sites are indexed in the MWDI data base. It bears no relationship to the location of the organization or to the organization's sites outside the United States that are not indexed in the MWDI. 
1500

$\overline{\text { IN SR }}$

MANDATORY Yes

PICTURE $9(3)$
MWDI_STATE

COMPONENT NAME

KEY Yes
1502

COMPONENT NUMBER

DATA TYPE Integer

LARGEST OR LONGEST VALUE 99

Data Values - This component contains a two-digit numeric code representing a State in which the organization operates sites, as long as one or more of those sites are indexed in the Master Water Data Index. Numeric codes for foreign countries will also appear, when applicable, as follows:

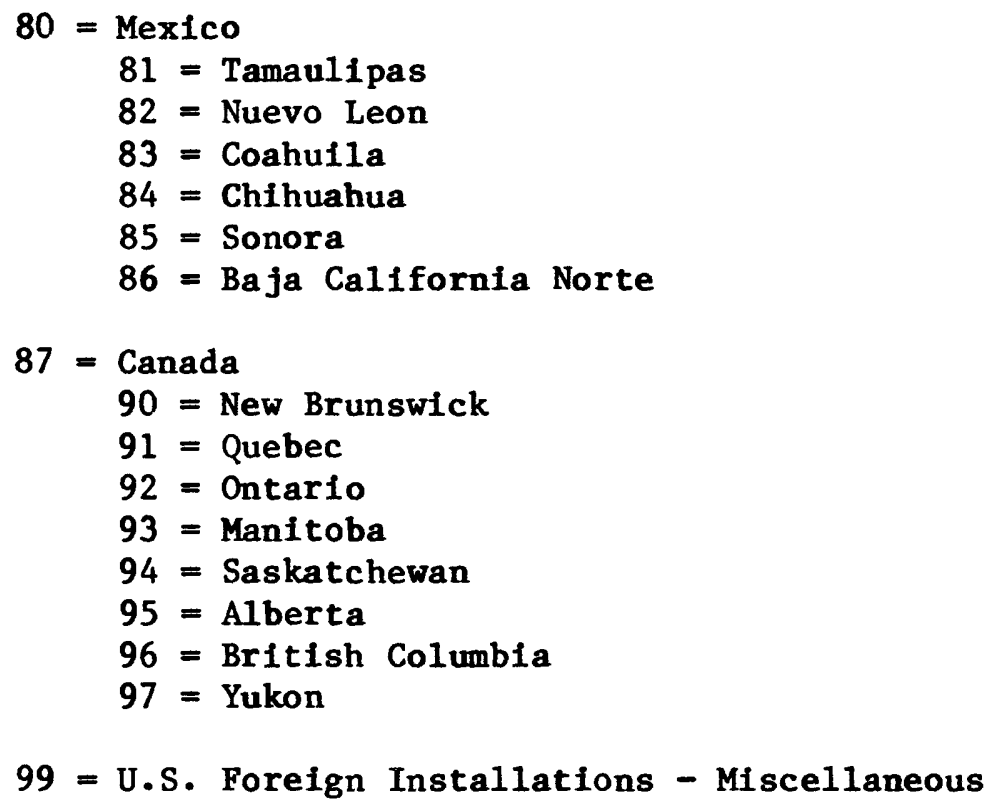

A complete list of State codes is contained in the Federal Information Processing Standards (FIPS) Publication 5-1, dated June 15, 1970, entitled "States and Outlying Areas of the United States."

General Description - The MWDI STATE component is valued for those States in which the organization operates sites that are indexed in the Master Water Data Index (MWDI). It bears no relationship to the location of the organization or to the organization's sites that are not indexed in the MWDI. 
1500

IN SR

MANDATORY No

PICTURE $9(7)$
MWDI_SW_QLTY

COMPONENT NAME

KEY Yes
1503

COMPONENT NUMBER

DATA TYPE Integer

LARGEST OR LONGEST VALUE $9,999,999$

Data Values - This is the total number of surface-water-quality sites operated by the organization that are located in the State identified in component 1502 (or country identified in component 1501) and are indexed in the Master Water Data Index (MWDI). For the same organization and State/country, the value in component 1503 must be less than or equal to the value in component 403.

General Description - The purpose of this component is to provide information on the number of the organization's surface-water-quality sites that are indexed in the MWDI. It should not be confused with component 403, SW QLTY, which is the total number of surface-water-quality sites operated by the organization, regardless of how many of them are indexed in the MWDI. If a site is indexed in the MWDI, detailed information about the site is available, including its name, location, period of record, and frequency of collection of the major surface-water-quality variables at the site. 
1500

IN SR

MANDATORY No

PICTURE 9(7)
MWDI_SW_QNTY

COMPONENT NAME

KEY

Yes

LARGEST OR LONGEST VALUE

$9,999,999$

Data Values - This is the total number of surface-water-quantity sites operated by the organization that are located in the state identified in component 1502 (or country identified in component 1501) and are indexed in the Master Water Data Index (MWDI). For the same organization and State/country, the value in component 1504 must be less than or equal to the value in component 404.

General Description - The purpose of this component is to provide information on the number of the organization's surface-water-quantity sites that are indexed in the MWDI. It should not be confused with component 404, SW QNTY, which is the total number of surface-water-quantity sites operated by the organization, regardless of how many of them are indexed in the MWDI. If a site is indexed in the MWDI, detailed information about the site is available, including its name, location, period of record, and frequency of collection of the major surface-water-quantity variables at the site. 
1500

IN SR

MANDATORY No

PICTURE 9(7)
MWDI_GW_QLTY

COMPONENT NAME

KEY Yes

DATA TYPE Integer
1505

COMPONENT NUMBER

LARGEST OR LONGEST REY 9,999,999

Data Values - This is the total number of ground-water-quality sites operated by the organization that are located in the State identified in component 1502 (or country identified in component 1501) and are indexed in the Master Water Data Index. For the same organization and State/country, the value in component 1505 must be less than or equal to the value in component 405.

General Description - The purpose of this component is to provide information on the number of the organization's ground-water-quality sites that are indexed in the MWDI. It should not be confused with component 405, GW_QLTY, which is the total number of ground-water-quality sites operated by the organization, regardless of how many of them are indexed in the MWDI. If a site is indexed in the MWDI, detailed information about the site is available, including its name, location, period of record, and frequency of collection of the major ground-water-quality variables at the site. 
1500

$\overline{\text { IN SR }}$

MANDATORY NO

PICTURE $9(7)$
MWDI_GW_QLTY

COMPONENT NAME

KEY Yes
1506

COMPONENT NUMBER

LARGEST OR LONGEST VALUE

$9,999,999$

DATA TYPE Integer

Data Values - This is the total number of ground-water-level sites operated by the organization that are located in the State identified in component 1502 (or country identified in component 1501) and are indexed in the Master Water Data Index (MWDI). For the same organization and State/country, the value in component 1506 must be less than or equal to the value in component 406.

General Description - The purpose of this component is to provide information on the organization's ground-water-level sites that are indexed in the MWDI. It should not be confused with component 406, GW LVL, which is the total number of ground-water-level sites operated by the organization, regardless of how many of them are indexed in the MWDI. If a site is indexed in the MWDI, detailed information about the site is avallable, including its name, location, period of record, and frequency of collection of the ground-water levels at the site. 
1500

IN SR

MANDATORY No

PICTURE $9(7)$
MWDI_GW_PUMP

COMPONENT NAME

KEY

Yes

LARGEST OR LONGEST VALUE

DATA TYPE Integer

Data Values - This is the total number of ground-water-pumpage sites operated by the organization that are located in the State identified in component 1502 (or country identified in component 1501) and indexed in the Master Water Data Index (MWDI). For the same organization and State/country, the value in component 1507 must be less than or equal to the value in component 407.

General Description - The purpose of this component is to provide information on the number of the organization's ground-water-pumpage sites that are indexed in the MWDI. It should not be confused with component 407, GW PUMP, which is the total number of ground-water-pumpage sites operated by the organization, regardless of how many of them are indexed in the MWDI. If a site is indexed in the MWDI, detalled information about the site is avallable, including its name, location, period of record, and frequency of collection of the ground-water-pumpage data at the site. 
1500

IN SR

MANDATORY NO

PICTURE 9(7)
MWDI GLGC

COMPONENT NAME

KEY

Yes
1508

COMPONENT NUMBER

DATA TYPE Integer

LARGEST OR LONGEST VALUE

$9,999,999$

Data Values - This is the total number of ground-water sites with geologic descriptions avallable, that are operated by the organization located in the State identified in component 1502 (or country identified in component 1501), and that are indexed in the Master Water Data Index (MWDI). For the same organization and State/country, the value in component 1508 must be less than or equal to the value in component 408 .

General Description - The purpose of this component is to provide information on the number of the organization's ground-water sites that are indexed in the MWDI for which there is information describing the geology in wich the sites are located. It should not be confused with component 408, GLGC, which is the total number of sites with geologic information operated by the organization, regardless of how many of them are indexed in the MWDI. If a site is indexed in the MWDI, detailed information about the site is available, including its name, location, period of record, and the geologic descriptors for the site. 
1500

IN SR

MANDATORY No

PICTURE $9(7)$
MWDI_WATER_USE

COMPONENT NAME

1509

COMPONENT NUMBER

KEY Yes

DATA TYPE Integer

LARGEST OR LONGEST VALUE

$9,999,999$

Data Values - Water-use data are not currently indexed in the Master Water Data Index. This component is, therefore, reserved for future use. 
1500

IN SR

MANDATORY No

PICTURE 9(7)
MWDI_MET_DATA

COMPONENT NAME

KEY

Yes
1510

COMPONENT NUMBER

DATA TYPE Integer

Data Values - This is the total number of meteorological sites operated by the organization that are located in the State identified in component 1502 (or country Identified in component 1501) and are indexed in the Master Water Data Index (MWDI). For the same organization and State/country, the value in component 1510 must be less than or equal to the value in component 410 .

General Description - The purpose of this component is to provide information on the number of the organization's meteorological sites that are indexed in the MWDI. It should not be confused with component 410, MET DATA, which is the total number of meteorological sites operated by the organization regardless of how many of them are indexed in the MWDI. If a site is indexed in the MWDI, detailed information about the site is avallable, including its name, location, period of record, and the frequency of collection of the major meteorological variables at the site. 
1500

IN SR

MANDATORY Yes

PICTURE $\quad \mathrm{X}(10)$
MWDI_DIRECTORY_TYPE

COMPONENT NAME

KEY Yes

LARGEST OR LONGEST VALUE
1518

COMPONENT NUMBER

DATA TYPE Char

10 characters

Data Values

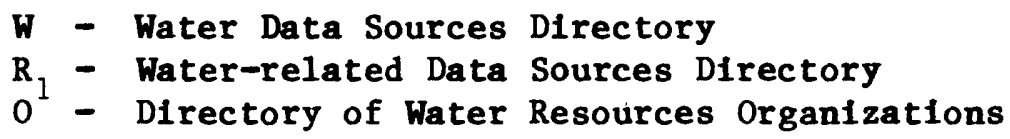

$0^{1}$ - Directory of Water Resources Organizations

General Description - MWDI DIRECTORY TYPE contains a combination of 1 to 10 codes, left-justified, to be used in retrieving specified types of directories. Each code may occur only once in this component. Additional codes will be added by the NAWDEX Program Office, as the need arises, to meet future directory needs.

j-

The alphabetic character 0 , not zero, is assigned. 
$\frac{1500}{5 R}$

MANDATORY N /A

PICTURE N/A
MWDI_COUNTIES

COMPONENT NAME

KEY N / A
1575

COMPONENT NUMBER

DATA TYPE SR

Data Values - Identifies the counties in which the organization operates sites that are Indexed in the Master Water Data Index. 
1575

IN SR

MANDATORY Yes

PICTURE 999
MWDI_COUNTY

KEY Yes

LARGEST OR LONGEST VALUE
1576

COMPONENT NUMBER

DATA TYPE Integer

Data Values - This component contains a three-digit numeric code for a county in which the organization operates one or more sites that are indexed in the Master Water Data Index. For sites operated outside the United States, there will be no occurrences of the MWDI COUNTIES schema record.

General Description - This component is valued for those counties in which there are one or more data collection sites operated by the organization, if those sites are indexed in the MWDI. The counties must be in the state identifled in component 1502, MWDI STATE. A complete list of county codes is contained in the Federal Information Processing Standards (FIPS) publication 6-3, dated December 15, 1979, entitled "Counties and County Equivalents of the States of the United States and the District of Columbia."

Note: Codes used to value this component include independent city codes for the States of Maryland, Missouri, Nevada, and Virginia; division codes for the State of Alaska; and county equivalents of Puerto Rico and the Virgin Islands. 
$\frac{0}{\text { IN SR }}$

MANDATORY N/A

PICTURE N/A
WATER_RELATED_DATA

COMPONENT NAME

KEY N /A
1600

COMPONENT NUMBER

DATA TYPE SR

Data Values - Information about water-related data that are collected and made available by the organization. Examples of water-related data include meteorological, water use, land use, oceanographic, agricultural, demographic, and other types of data. Water-related data are defined as any data having significance to users of water data or to those conducting water-resource projects or investigations. 
1600

IN SR

MANDATORY No

PICTURE X(8)
PARAMETER_CODE

COMPONENT NAME

KEY Yes

LARGEST OR LONGEST VALUE
1601

COMPONENT NUMBER

DATA TYPE Char

Data Values - This component contains an eight-character code which identifies the type of water-related data available.

General Description - The purpose of this component is to identify the individual types of water-related data that may be available from the organization. A different parameter code is assigned to each major category or subcategory of water-related data identified. A complete list of all codes assigned may be obtained from: National Water Data Exchange, U.S. Geological Survey, 421 National Center, Reston, Virginia 22092. 
1600

$\overline{\text { IN SR }}$

MANDATORY No

PICTURE 9(4)
BEGIN YEAR

COMPONENT NAME

KEY No

LARGEST OR LONGEST VALUE
1602

COMPONENT NUMBER

DATA TYPE Integer

Data Values - This component contains a four-digit numeric value which identifies the year that the water-related data being reported were first collected by the organization.

General Description This component identifies the calendar year in which the organization first began to collect the water-related data that are being made available. 
1600

IN SR

MANDATORY No

PICTURE 9(4)
END_YEAR

COMPONENT NAME

KEY

No
1603

COMPONENT NUMBER

DATA TYPE Integer

Data Values - This component contains a four-digit numeric value which identifies the year that data-collection activities for the water-related data being reported were ceased. If the organization is currently collecting the water-related data reported, this component is not valued.

General Description - This component identifies the calendar year in which the organization discontinued collection of the water-related data being reported. If, at a future date, the collection of the water-related data is resumed, the former end date is deleted. 
1600

IN SR

MANDATORY No

PICTURE 9(7)
NUMBER_OF_SITES

COMPONENT NAME

KEY No

DATA TYPE Integer
1604

COMPONENT NUMBER

LARGEST OR LONGEST VALUE 9,999,999

Data Values - This is the total number of sites, if applicable, at which the reported water-related data are, or have been, collected by the organization.

General Description - The purpose of this component is to provide information on the number of sites at which the organization has the reported water-related data available. Some types of water-related data are collected on an areal or nonpoint source basis. In these cases, this component will not be valued. 
1600

$\overline{\text { IN SR }}$

MANDATORY No

PICTURE 9(8)
NUM_OBSERVATIONS

COMPONENT NAME

KEY No

LARGEST OR LONGEST VALUE
1605

COMPONENT NUMBER

DATA TYPE Integer

Data Values - This is the total number of occurrences or observations, if applicable, for which the reported water-related data are, or have been, collected and are available.

General Description - Many types of water-related data are collected on an areal basis and the number-of-sites component (component 1604) is not applicable. The number of occurrences or observations of these data may, then, be reported to indicate the volume of data available to the user. 
1600

$\overline{\mathrm{IN} \mathrm{SR}}$

MANDATORY

No

PICTURE $\quad \mathrm{X}(1)$
GEOGRAPHIC_AREA

COMPONENT NAME

KEY

No
1606

COMPONENT NUMBER

DATA TYPE Char

LARGEST OR LONGEST VALUE

S

Data Values - This component contains a one-character alphabetic code that describes the geographic area encompassed by the water-related data reported and avallable.

General Description:

Code $\quad$ Meaning

A Multicounty - Two or more counties, all in the same State, but not encompassing the entire state.

C One County - All the data available are for a single county.

I Multicountry (International) - Data from more than one country are avallable.

M Multistate (Province) - Data from more than one State or Province are available, and all data are for a single country.

N Nationwide - The available data span an entire country and are limited to that single country.

S Statewide - The available data span an entire State or Province and are limited to that single State or Province. 
$\frac{1600}{\text { IN SR }}$

MANDATORY

No

PICTURE

$\mathrm{X}(1)$
OBS_FREQUENCY

COMPONENT NAME

KEY

No
1607

COMPONENT NUMBER

DATA TYPE Char

Data Values - This component contains a one-character alphabetic code that best describes the frequency at which the water-related data reported are collected or measured.

General Description:

Code

Frequency

A

B

C

D

E

I

$\mathrm{J}$

$\mathbf{M}$

N

0

$\mathbf{P}$

Q

R

S

$\mathrm{U}$

W

$\mathrm{X}$

$Y$

Z
Annual (Once per year)

Other periodic (Less than once per year)

Continuous, Year-round - Nonrecorder

Continuous, Seasonal - Nonrecorder

Eliminated Activity - Data are no longer being collected

Continuous, Year-round, Recorder used

Continuous, Seasonal, Recorder used

Monthly, Year-round

Monthly, Seasonal

Daily, Year-round

Da1ly, Seasonal

Quarter1y, Year-round

Quarterly, Seasonal

Semiannual (Twice per year)

Unique (One-time only) measurement

Weekly, Year-round

Weekly, Seasonal

Seasonal (No time period specifled)

Data collected at an irregular or unspecified frequency 
1600

$\overline{\text { IN SR }}$

MANDATORY

No

PICTURE $X(1)$
STORAGE_MEDIA

COMPONENT NAME

KEY No
1608

COMPONENT NUMBER

DATA TYPE Char

Data Values - This component contains a one-character alphabetic code that describes the type(s) of media used to store the water-related data reported.

General Description:

Code $\quad$ Meaning

C Computer recognizable - The data are stored on media that can be read by a computer. This might be punched cards, paper tape, magnetic tape, magnetic disk, drum, or some similar device.

D Computer and published - Data are stored in both computer recognizable and published form.

E Computer and microform - Data are stored in both computer recognizable and micoform formats.

F

Computer, published, and microform - Data are stored in computer recognizable, published, and microform formats.

G

Published and microform - Data are stored in both published and microform formats.

M

Microform - Printed data which are stored in reduced size on roll microfilm, microfiche, aperture cards, or some other type of microfilm.

Published - The data are avallable in printed form. 
1600

$\overline{\text { IN SR }}$

MANDATORY No

PICTURE $\mathrm{X}(5)$
OTHR_SOURCE

COMPONENT NAME

KEY No
1610

COMPONENT NUMBER

DATA TYPE Char

Data Values - This is the NAWDEX Agency Code that identifies another organization that is a source of the organization's water-related data.

General Description - A complete description of the NAWDEX Agency Code may be found in this dictionary under component number 1 . This is the same code that is also stored in component 502 (OT SRC AGCY). If this component is valued, schema record 500 (OTHR SOURCE) must àlso be valued. 
1600

$\overline{\text { IN SR }}$

MANDATORY Yes

PICTURE $\mathbf{X}(10)$
WRD_DIRECTORY_TYPE

COMPONENT NAME

KEY Yes

LARGEST OR LONGEST VALUE
1618

COMPONENT NUMBER

DATA TYPE Char

Data Values

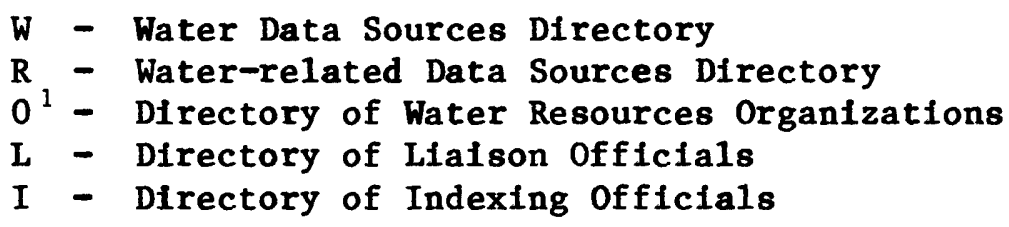

Genera1 Description - WRD DIRECTORY TYPE contains a combination of 1 to 10 codes, left-justified, to be used in retrieving specified types of directories. Each code may occur only once in this component. Additional codes will be added by the NAWDEX Program Office, as the need arises, to meet future directory needs.

The alphabetic character 0 , not zero, is assigned. 


\section{SELECTED REFERENCES}

Edwards, M. D., 1980, NAWDEX: A key to finding water data: Washington, D.C., U.S. Geological Survey Pamphlet, 15 p.

Edwards, M. D., and Josefson, B. M., 1982, Identification codes for organizations listed in computerized data systems of the U.S. Geological Survey: U.S. Geological Survey Open-File Report 82-921, 114 p.

Knecht, W. A., and Edwards, M. D., 1980, Definitions of components of the water data sources directory maintained by the National Water Data Exchange: U.S. Geological Survey Open-File Report 79-1541, 106 p. [Superseded by subject report of the same title.]

Josefson, B. M., and Blackwe11, C.D., 1982, Directory of Assistance Centers of the National Water Data Exchange (NAWDEX): U.S. Geological Survey Open-File Report 82-925, 31 p.

MRI Systems Corporation, 1972, General information manual: 23 p. 1974, SYSTEM 2000 reference manual: 655 p.

Perry, R. A., and Williams, 0. 0., 1982, Definitions of components of the master water data index maintained by the National Water Data Exchange: U.S. Geological Survey Open-File Report 82-327, 269 p.

U.S. Department of Commerce, National Bureau of Standards, 1970, States and outlying areas of the United States: Federal Information Processing Standards (FIPS) Publication 5-1, 4 p.

1976, Countries, dependencies, and areas of special sovereignty:

Federal Information Processing Standards (FIPS) Publication 10-2, 25 p.

1978, Codes for named populated places and related entities of the States of the United States, Volumes 1 and 2: Federal Information Processing Standards (FIPS) Publication 55, 1,946 p.

1979, Counties and county equivalents of the States of the United States and the District of Columbia: Federal Information Processing Standards (FIPS) Publication 6-3, $35 \mathrm{p}$. 


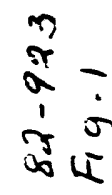

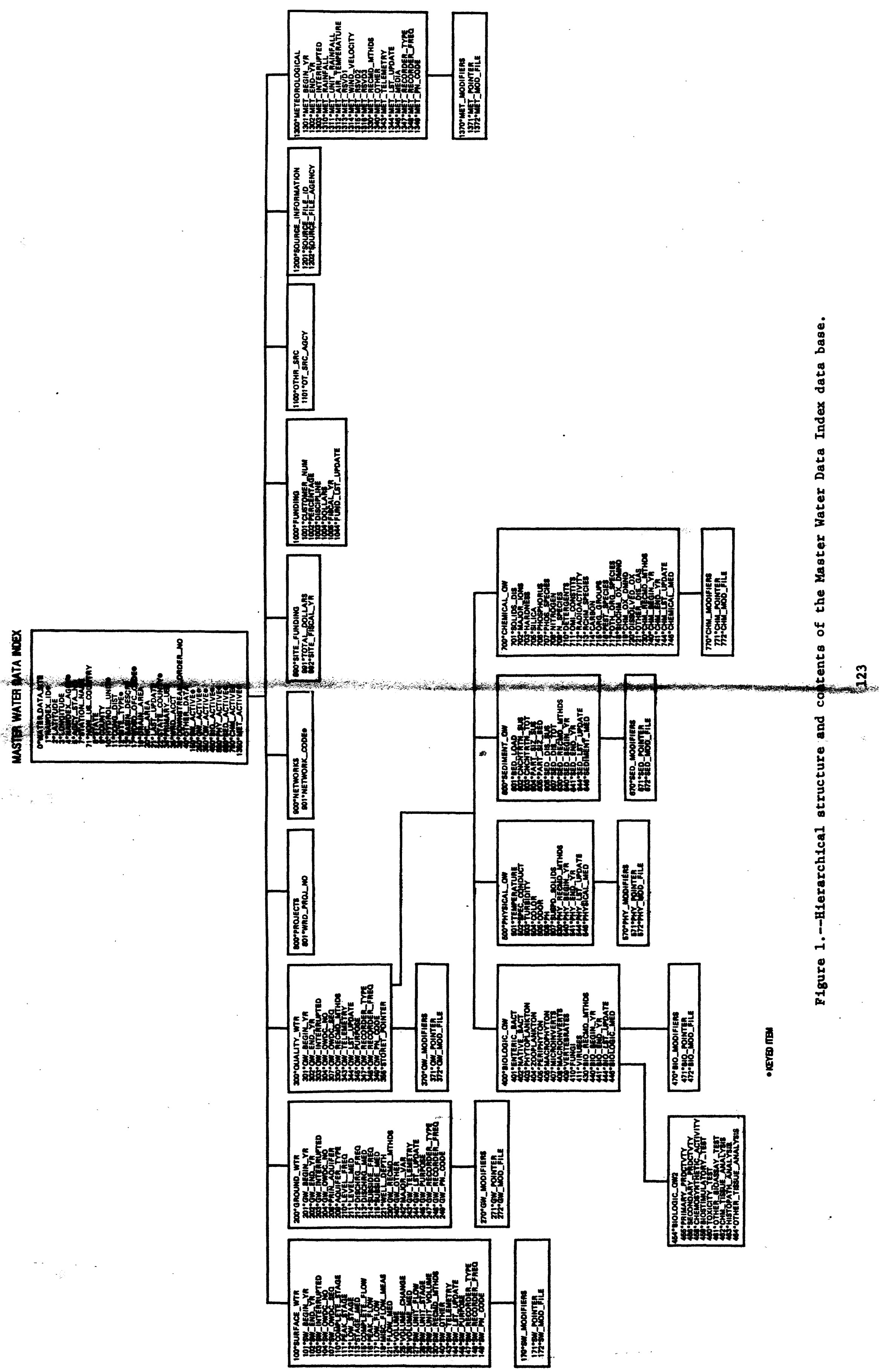


$\frac{7}{2} r$
$\frac{1}{1} \cdot$
$x^{3}$

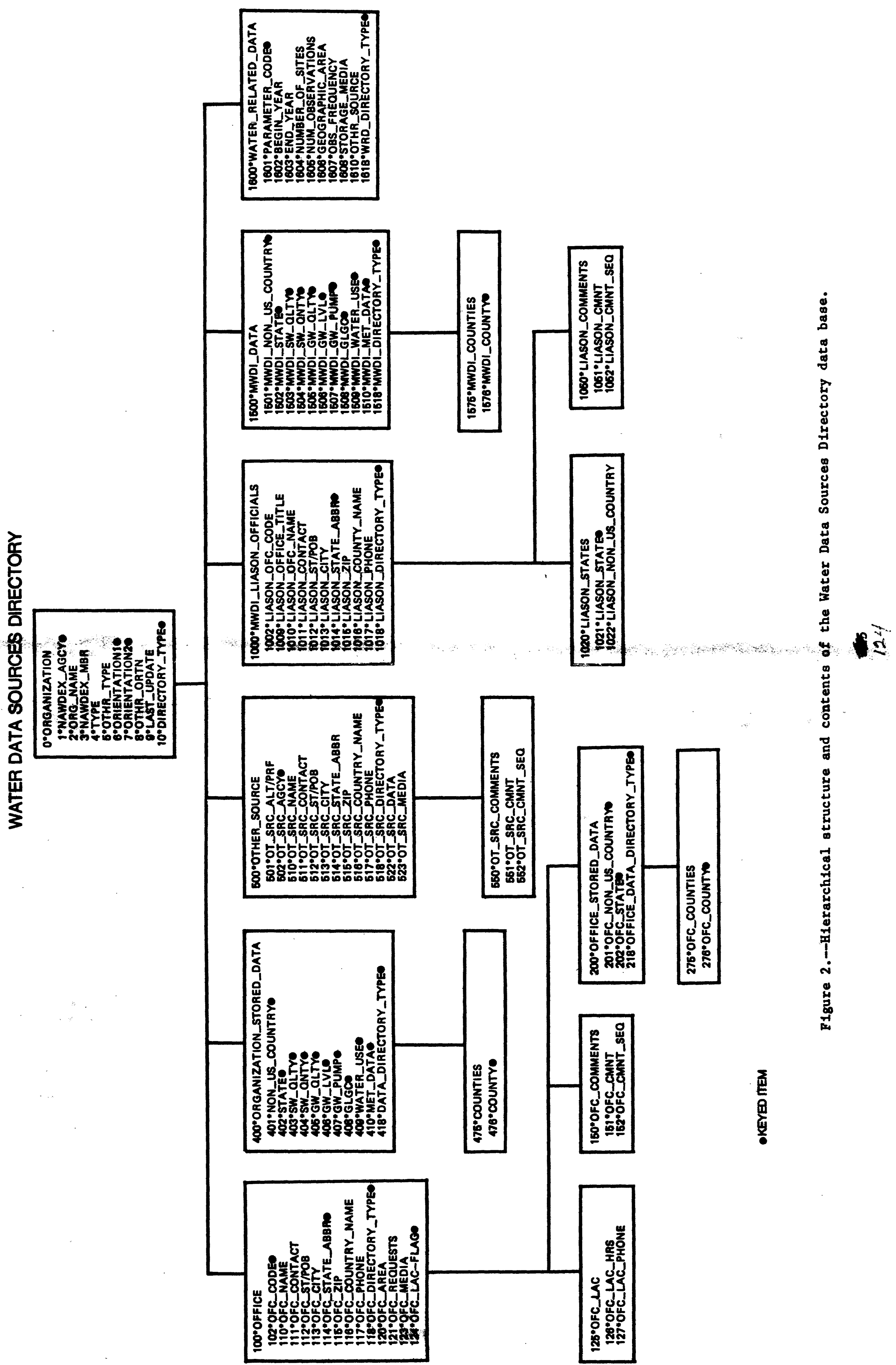

